\title{
1 Sulfur-doped Cobalt Oxide Nanowires as Efficient Electrocatalysts for Iodine
}

\section{Reduction Reaction}

3 Wentao Liang ${ }^{\mathrm{a}, \dagger}$, Kaicai Fan ${ }^{\mathrm{a}, \dagger}$, Yemei Luan ${ }^{\mathrm{a}, \mathrm{b}}$, Zhijin Tan $^{\mathrm{a}}$, Mohammad Al-Mamun ${ }^{\mathrm{a}}$, Yun

$4 \quad$ Wang $^{\mathrm{a}}$, Porun Liu ${ }^{\mathrm{a},{ }^{*}}$, Huijun Zhao, ${ }^{\mathrm{a}, *}$

$5{ }^{\text {a }}$ Centre for Clean Environment and Energy, School of Environment and Science, Griffith

6 University, Gold Coast Campus, Queensland, 4222, Australia

$7 \quad{ }^{b}$ College of Textile and Garment, Hebei University of Science and Technology, Shijiazhuang

$8 \quad 050018$, P. R. China

9 *Email: $\underline{\text { h.zhao@griffith.edu.au, p.liu@ griffith.edu.au, Tel: (+61)-7-55528261 }}$

10

11 Abstract: Sulfur-doped cobalt oxide $\left(\mathrm{S}_{-}-\mathrm{Co}_{3} \mathrm{O}_{4}\right)$ crystals exhibit excellent catalytic activities towards multiple useful reactions, however, the impact of the structural properties on the resultant catalytic activities has been overlooked in the past. We demonstrate a facile vaporphase hydrothermal (VPH) doping approach to effectively create electrocatalytically active surface sulfur species on the chemical bath deposited polycrystalline $\mathrm{Co}_{3} \mathrm{O}_{4}$ nanowires for iodine reduction reaction (IRR). The dye-sensitized solar cells (DSSCs) equipped with the S$\mathrm{Co}_{3} \mathrm{O}_{4}$ nanowire film as the counter electrode (CE) achieve a best energy conversion efficiency of $6.78 \%$, which is comparable to those of DSSCs with commercial Pt CE $(7.36 \%)$. The impact of film structure, VPH temperature and VPH duration on the resultant structures as well as the electrocatalytic activities has been comprehensively studied. More importantly, our results manifest a close correlation between the surface sulfur dopant level and the key electrocatalytic activity indicators. The VPH approach could be further extended to the fabrication of low-cost, high-performance nanomaterials for energy conversion applications. 
Keywords: Vapor-phase hydrothermal method; Sulfur doping; Iodine reduction reaction;

Electrocatalyst; Dye-sensitized solar cells.

${ }^{\dagger}$ These author contributed equally to the work.

\section{Introduction}

Over last decades, there have been increasing interests in the exploitation and utilization of renewable energy among the society due to the exacerbated greenhouse gas emissions and fossil fuel deficiency. Dye-sensitized solar cells (DSSCs), since their advent, have emerged as one of the most promising alternatives to the traditional $p-n$ junction solar cells, and attracted widespread interests due to their simple fabrication, environmental friendliness and cost-effectiveness [1, 2]. Notable research breakthroughs in redox couples, organic dye sensitizers, nanostructured photoanodes, new electrocatalysts for counter electrode (CE) have been achieved, and the highest power conversion efficiency (PCE) has reached over 14\% [3, 4]. However, the best-performing DSSCs to date are still equipped with high-cost platinum (Pt) electrocatalysts, the use of which impose a limitation on the large-scale DSSCs application. Thus, researches have been focused on the development of low-cost, highly efficient electrocatalysts to replace benchmark Pt materials for high-performance DSSCs [57].

In traditional DSSCs where iodide/tri-iodide $\left(\mathrm{I}^{-} / \mathrm{I}_{3}{ }^{-}\right)$redox couple solution is used as the electrolyte, the role of an electrocatalyst is to catalytically reduce $\mathrm{I}_{3}^{-}$to $\mathrm{I}^{-}$(in which iodine reduction reaction, IRR, is the limiting step) whilst collecting the electrons from external circuit. Current research strategies to elevate the overall electrocatalytic performance of Ptlow or Pt-free electrocatalyst include: i) exploration of new electrocatalytic materials, such as carbon materials $[8,9]$, polymers $[10,11]$, metal compounds (oxides [12-14], sulphides [1517], selenides [18, 19], nitrides [20, 21] and carbides [22, 23]); ii) creation of active sites via 
nanoscaled engineering, for instance, the synthesis of $\alpha-\mathrm{Fe}_{2} \mathrm{O}_{3}$ crystals with exposed active (012) and (104) surfaces [24] or enlargement of active edge sites on $\mathrm{MoS}_{2}$ electrode by patterning [25]; iii) optimizing substrate support, such as mesoporous carbon [26], and fluorine-doped tin oxide (FTO) [27] and tin-doped indium oxide (ITO) nanoarray supports [28]; iv) utilization of the composite materials for synergetically enhanced performance and improved stabilities $[29,30]$. v) chemical doping [31, 32]. The incorporation of dopants to materials plays different roles in determining the overall electrocatalytic reaction pathways. For carbon-based materials, the doping of heteroatoms will produce local strains and structural deformations [33]. The incurred electron charges in the delocalized carbon framework will improve the electron conduction and also electrocatalytic activity without altering the bulk properties [34]. For conducting polymer, on the other hand, the introduction of dopant atoms into the polymer structure will induce remarkably enhanced conductivity that facilitates electron transport in the polymer main chain [35]. Compared to carbon and polymer materials, however, cation [36] or anion [31] doped inorganic metal compounds as the CE electrocatalysts for DSSCs have been rarely explored. Notably, Li and co-workers reported that PCE of DSSCs using sulphur-doped nickel oxide as counter electrode electrocatalyst was has been remarkably improved compared to the pristine nickel oxide film [31]. However, although chemical doping is effective for activity enhancement, the inherent relationship between the dopant levels and the electrocatalytic activity remains unclear. We believe that an insight on this aspect will provide valuable guidance to further improve the electrocatalytic activities.

Spinel-type cobalt oxide $\left(\mathrm{Co}_{3} \mathrm{O}_{4}\right)$ has been an essential p-type semiconducting material for heterogeneous catalysis, lithium-ion battery, electrochemical pseudocapacitors and gas sensing applications [37]. In this study, it was selected as the potential electrocatalytic materials due to its good catalytic activity, charge capacity and chemical stability. It has been 
reported that the incorporation of anion dopants (such as nitrogen [38, 39] and fluorine [40]) into $\mathrm{Co}_{3} \mathrm{O}_{4}$ crystals could dramatically enhance the catalytic (Hg oxidation), electrocatalytic (oxygen reduction reaction) and photocatalytic (hydrogen generation) performance of this material. In this work, we report the preparation of $\mathrm{S}^{-\mathrm{Co}_{3} \mathrm{O}_{4}}$ crystals on conductive FTO substrate as the counter electrode for DSSCs via a facile, low-temperature in-situ vapor-phase hydrothermal (VPH) doping technique. Our characterization and solar cell evaluation results have demonstrated a close relationship between the sulfur dopant level of the materials and their electrocatalytic activities.

\section{Experimental}

\subsection{Materials}

$\mathrm{Co}\left(\mathrm{NO}_{3}\right)_{2} \cdot 6 \mathrm{H}_{2} \mathrm{O}(98 \%), \mathrm{Al}_{2} \mathrm{~S}_{3}$, and $\mathrm{LiClO}_{4}(98 \%)$ were obtained from Sigma-Aldrich. Anhydrous LiI, $\mathrm{I}_{2}$, and acetonitrile ( $\mathrm{ACN}$ ) were purchased from Merck. 4-tert-Butylpyridine (TBP, 96\%) and tert-butanol (TBA, 99.5\%) were received from Acros. Ethanol (ACS reagent, 99.5\%) was purchased from Aldrich Chemical Co. The commercial $\mathrm{TiO}_{2}$ electrodes, $\mathrm{N} 719$ dye, Pt electrodes and electrolyte were purchased from Greatcellsolar (Dyesol). All chemicals mentioned above were used without further purification. Deionized water (Milli Q, 18.2 $\mathrm{M} \Omega \cdot \mathrm{cm}$ ) was used throughout the work.

\subsection{Preparation of Electrodes}

S- $\mathrm{Co}_{3} \mathrm{O}_{4}$ thin films were fabricated by in-situ $\mathrm{VPH}$ doping treatment of the obtained $\mathrm{Co}_{3} \mathrm{O}_{4}$ nanowire film on the FTO glasses. Thin films of $\mathrm{Co}_{3} \mathrm{O}_{4}$ nanowire arrays were firstly deposited on FTO glass substrates using chemical bath deposition (CBD) followed by a pyrolysis treatment. Typically, a FTO substrate was suspended with conductive side facing downwards in an aqueous solution $(50 \mathrm{~mL})$ containing $6.25 \mathrm{wt} \%$ of urea and $0.15 \mathrm{M}(4.4 \mathrm{~g})$ of cobalt nitrate at $90^{\circ} \mathrm{C}$ for varied durations $(3,4,5$ and $6 \mathrm{~h})$. After deposition, the obtained 
cobalt hydroxide carbonate films on the FTO were converted to $\mathrm{Co}_{3} \mathrm{O}_{4}$ by pyrolysis in air at $400{ }^{\circ} \mathrm{C}$ for 2 hours. Secondly, the $\mathrm{Co}_{3} \mathrm{O}_{4}$ nanowire film was in-situ doped in VPH reactor [41, 42] where $\mathrm{H}_{2} \mathrm{~S}$ gas was produced by slow hydrolysis of $\mathrm{Al}_{2} \mathrm{~S}_{3}$ at the presence of trace amount of water vapor generated after initial heating. Typically, $\mathrm{Al}_{2} \mathrm{~S}_{3}(0.26 \mathrm{~g})$ and $60 \mu \mathrm{L}$ water was placed in VPH reactor where the $\mathrm{Co}_{3} \mathrm{O}_{4}$ film on FTO substrate was held above the reactants (Fig. 1). The VPH treatments were carried out at various temperatures $(70,90,120,150$, $180{ }^{\circ} \mathrm{C}$ for $6 \mathrm{~h}$ ) and with durations $\left(15 \mathrm{~min} \sim 12 \mathrm{~h}\right.$ at $\left.90{ }^{\circ} \mathrm{C}\right)$. The as-obtained $\mathrm{S}-\mathrm{Co}_{3} \mathrm{O}_{4}$ films were rinsed with $\mathrm{CS}_{2}$ solvent to remove the sulfur generated during the VPH treatment prior to structural characterization or electrochemical tests.

\subsection{Solar Cell Assembly}

Commercial $\mathrm{TiO}_{2}$ electrodes with $\mathrm{TiO}_{2}$ paste coated on FTO substrates were purchased and sintered at $450{ }^{\circ} \mathrm{C}$ for $30 \mathrm{~min}$ in air prior to use. After dye (N719) loading for $24 \mathrm{~h}$, the dye-sensitized $\mathrm{TiO}_{2}$ electrode was coupled with one of the $\mathrm{CEs}\left(\mathrm{Co}_{3} \mathrm{O}_{4} \mathrm{CE}, \mathrm{S}-\mathrm{Co}_{3} \mathrm{O}_{4} \mathrm{CEs}\right.$, or Pt CE) to fabricate the DSSC; these two electrodes were separated by a $60 \mu \mathrm{m}$ thick Surlyn gasket and sealed by hot press. The electrolyte was injected into the gap between the two electrodes under vacuum through a hole on CE electrode which was sealed with hot-melt glue.

\subsection{Characterizations}

X-ray diffraction patterns were analysed with a Bruker D8 X-ray diffractometer operated at $40 \mathrm{kV}$ and $25 \mathrm{~mA}$. Raman spectra were collected with a Renishaw inVia confocal Raman microscope using a $532 \mathrm{~nm}$ laser. The X-ray photoelectron spectroscopy (XPS) data was obtained using a Kratos Analytical Axis Ultra X-ray photoelectron spectrometer equipped with a monochromatic $\mathrm{Al} \mathrm{X}$-ray source $(\mathrm{Al} \mathrm{K \alpha}, 1.487 \mathrm{keV})$. The $\mathrm{C}$ 1s peak was used as the charge reference with a binding energy of $284.8 \mathrm{eV}$. The morphological properties of samples were investigated by a JSM-7100 field emission scanning electron microscope. The 
microstructures were examined by field emission TEM Tecnai 20 (F20) with an accelerating voltage of $200 \mathrm{kV}$.

Cyclic voltammetric (CV) measurements were performed with a CHI 760 electrochemical workstation ( $\mathrm{CH}$ Instruments, Inc., USA), using a conventional three-electrode system in which a $\mathrm{CE}$, a platinum mesh, and a $\mathrm{Ag} / \mathrm{AgCl}$ electrode were used as the working electrode, counter electrode, and reference electrode, respectively. A solution of $10.0 \mathrm{mM} \mathrm{LiI}, 1.0 \mathrm{mM}$ $\mathrm{I}_{2}$, and $0.1 \mathrm{M} \mathrm{LiClO}_{4}$ in $\mathrm{ACN}$ was used as the electrolyte for all $\mathrm{CV}$ measurements. $\mathrm{CV}$ curves were recorded at a scan rate of $100 \mathrm{mV} / \mathrm{s}$. Tafel polarization curves and electrochemical impedance spectra (EIS) were obtained using symmetrical cells, at a scan rate of $50 \mathrm{mV} / \mathrm{s}$. The film area of CE was confined to be $0.25 \mathrm{~cm}^{2}$. The photocurrent densityvoltage characteristic was measured using a computer-controlled scanning potentiostat (Model 362, Princeton Applied Research, US). A 500 W Xe lamp (Trusttech Co., Beijing) with an AM 1.5G filter (Sciencetech, Canada) was used as the light source. The light intensity was calibrated with a radiant power meter (Newport, 70260).

\section{Results and Discussion}

\subsection{Structural properties and electrocatalytic performance}

The crystal and structural properties of $\mathrm{Co}_{3} \mathrm{O}_{4}$ sample and the best-performing S$\mathrm{Co}_{3} \mathrm{O}_{4}$ sample (obtained from $\mathrm{VPH}$ treatment at $90{ }^{\circ} \mathrm{C}$ for $6 \mathrm{~h}$ ) were characterized by X-ray diffraction (XRD) analysis and Raman spectra. The XRD data of both samples before and after VPH doping treatment (Fig. 2a) show similar diffraction patterns. Diffraction peaks centered at $2 \theta=31.5,37.0,45.0,55.9$ and $59.5^{\circ}$ are ascribed to (220), (311), (400), (422) and (511) planes of spinel $\mathrm{Co}_{3} \mathrm{O}_{4}$ (cubic, $a=8.056 \AA$, space group $F d-3 m$, JCPDS: PDF-74-1656, ICSD: 27497), respectively. In addition, minor shifts of the diffraction peaks after VPH doping indicate an increase in lattice strain, which is due 
to sulfur incorporation into the crystal lattice. The crystal phase of these two samples are further confirmed with their Raman spectra, which demonstrate 5 peaks corresponding to three $\mathrm{F}_{2 \mathrm{~g}}$ modes (at about 193, 519 and $616 \mathrm{~cm}^{-1}$ ), one $\mathrm{E}_{\mathrm{g}}$ mode (at about $480 \mathrm{~cm}^{-1}$ ) and one $\mathrm{A}_{1 \mathrm{~g}}$ mode (at about $688 \mathrm{~cm}^{-1}$ ) of spinel $\mathrm{Co}_{3} \mathrm{O}_{4}$ crystals (Fig. 2b) [43]. Compared to the peaks of bulk $\mathrm{Co}_{3} \mathrm{O}_{4}$ crystals in literatures, all Raman peaks observed in this study show a slight red shift due to an agglomeration of nanosized $\mathrm{Co}_{3} \mathrm{O}_{4}$ particles [44]. Notably, the most dominant peak $\left(\mathrm{A}_{1 \mathrm{~g}}\right)$ of the $\mathrm{S}-\mathrm{Co}_{3} \mathrm{O}_{4}$ sample $\left(686.0 \mathrm{~cm}^{-1}\right)$ has shift to lower frequencies compared to the pristine $\mathrm{Co}_{3} \mathrm{O}_{4}$ sample $\left(689.8 \mathrm{~cm}^{-1}\right)$. As the $\mathrm{A}_{1 \mathrm{~g}}$ mode is referred to the symmetric stretching of the Co-O bonds, this red shift may allude to a decrease in the bond strength, after the substitution of oxygen atoms in spinel $\mathrm{Co}_{3} \mathrm{O}_{4}$ crystal by sulfur counterparts.

The morphologies and microstructures of the as-synthesized $\mathrm{Co}_{3} \mathrm{O}_{4}$ and $\mathrm{S}-\mathrm{Co}_{3} \mathrm{O}_{4}$ samples were characterized using scanning electron microscopy (SEM) and transmission electron microscopy (TEM). The SEM images of samples before and after VPH treatment (Fig. 3a, e) confirmed that the uniform wire-like array morphology has been kept intact. The nanowires grow from the substrate and join with neighbors at the top forming bundle-like tips. The TEM images (Fig. 3b, f) reveal that the nanowires are consisted of multiple closelypacked $\mathrm{Co}_{3} \mathrm{O}_{4}$ nanocrystals with the size of about a few tens to hundreds $\mathrm{nm}$. The polycrystalline characteristics of the nanowires have been further confirmed in the selectedarea electron diffraction (SAED) patterns (Fig. 3c, g) showing reflections of (111), (220), (311), (400), (422), (511) and (440) crystal planes. High-resolution TEM (HRTEM) images (Fig. 3d, h) show a lattice spacing of $4.7 \AA$ (111 plane), apparel to the crystal surface, confirming that the crystals are dominantly enclosed with $\{111\}$ facets. No formation of $\mathrm{Co}_{3} \mathrm{~S}_{4}$ has been observed in our samples [45]. The particle-packed, tip-joined nanowire 
structure provide multiple electrical pathways for charge carriers within the network to ensure excellent performance.

X-ray photoelectron spectroscopy (XPS) was performed to analyze the surface chemical composition of the samples (Fig. 4). The elemental concentrations on the surface were measured $\mathrm{Co} 21.96 \%$, O $46.44 \%$, and $\mathrm{C} 31.60 \%$ for $\mathrm{Co}_{3} \mathrm{O}_{4}$, and $\mathrm{Co}$ $15.20 \%, \mathrm{O} 33.30 \%, \mathrm{C} 23.33 \%$, and $\mathrm{S} 28.17 \%$ for $\mathrm{S}-\mathrm{Co}_{3} \mathrm{O}_{4}$, respectively. Notably, compared to the general low sulfur dopant concentration in the literature $(<10 \%)[39$, 40], a relatively high surface sulfur element has been achieved. In high-resolution Co $2 \mathrm{p}$ spectra, the Co $2 \mathrm{p}_{3 / 2}$ core level curves of both $\mathrm{Co}_{3} \mathrm{O}_{4}$ and $\mathrm{S}-\mathrm{Co}_{3} \mathrm{O}_{4}$ samples composed of strong major peaks and weak shake-up satellite peaks (Fig. 4b). In particular, the core electrons centered at $779.7 \mathrm{eV}$ and $780.9 \mathrm{eV}$ for $\mathrm{Co}_{3} \mathrm{O}_{4}$ sample represents the predominant $\mathrm{Co}$ (III)-O and $\mathrm{Co}$ (II)-O bonds, respectively. They have been shifted to lower binding energy direction (779.1 and 780.6eV) after VPH sulfur doping treatment. In the $\mathrm{O} 1 \mathrm{~s}$ spectrum of $\mathrm{Co}_{3} \mathrm{O}_{4}$ sample (Fig. 4c), the peak centered at 529.9 $\mathrm{eV}$ can be assigned as the lattice oxygen $\left(\mathrm{O}_{\text {lat }}\right)$ and the other peaks are attributed to the absorbed non-stoichiometric oxygens, respectively. It is to note that a dramatic decrease in magnitude of the $\mathrm{O}_{\text {lat }}$ peak is observed after doping treatment verifying that the surface oxygens have been effectively substituted by sulfur atoms. Furthermore, the $\mathrm{S} 2 \mathrm{p}_{3 / 2}$ peaks of $\mathrm{S}-\mathrm{Co}_{3} \mathrm{O}_{4}$ sample centered at $162.7(42.89 \%), 163.7$ (30.04\%), $166.6(7.84 \%)$ and $169.3 \mathrm{eV}(19.24 \%)$ are ascribed to be sulfide $\left(\mathrm{S}^{2-}\right)$, polysulfide $\left(\mathrm{S}_{\mathrm{n}}{ }^{2-}\right)$, sulfite $\left(\mathrm{SO}_{3}{ }^{2-}\right)$ and sulfate species $\left(\mathrm{SO}_{4}{ }^{2-}\right)$ on the surface $(\mathrm{Fig} .4 \mathrm{~d})$.

It was reported that the anion-doped $\mathrm{Co}_{3} \mathrm{O}_{4}$ nanoparticles demonstrated excellent electrocatalytic activities towards significant chemical reactions, for instance, oxygen reduction reaction [38, 46], hydrogen generation from water/ethanol [40], and oxygen evolution reaction [47]. In this study, the resultant $\mathrm{S}_{-}-\mathrm{Co}_{3} \mathrm{O}_{4}$ film has been used as the $\mathrm{CE}$ 
towards IRR in DSSCs [48-50]. Fig. 5 shows the photocurrent density-voltage $(J-V)$ curves of the DSSCs assembled with $\mathrm{Co}_{3} \mathrm{O}_{4}, \mathrm{~S}-\mathrm{Co}_{3} \mathrm{O}_{4}$, and Pt CEs. The photovoltaic parameters: opencircuit voltage $\left(V_{O C}\right)$, short-circuit current density $\left(J_{S C}\right)$, fill factor $(F F)$, and PCE $(\eta)$ are listed in Table. 1 (sample: $\mathrm{Co}_{3} \mathrm{O}_{4}, \mathrm{~S}-\mathrm{Co}_{3} \mathrm{O}_{4}-2$ and $\mathrm{Pt}$ ). The DSSC equipped with $\mathrm{Co}_{3} \mathrm{O}_{4} \mathrm{CE}$ display a poor photovoltaic characteristics $\left(J_{S C}, 3.43 \mathrm{~mA} / \mathrm{cm}^{2} ; V_{O C}, 0.57 \mathrm{~V} ; F F, 0.11\right.$ and $\eta$, $0.21 \%$ ), confirming the negligible electrocatalytic activity of pristine $\mathrm{Co}_{3} \mathrm{O}_{4}$ towards IRR. In strong contrast, the photovoltaic parameters of DSSCs with a $\mathrm{S}-\mathrm{Co}_{3} \mathrm{O}_{4} \mathrm{CE}$ were improved significantly, with a $J_{S C}$ of $15.03 \mathrm{~mA} / \mathrm{cm}^{2}$, a $V_{O C}$ of $0.68 \mathrm{~V}$, an $F F$ of 0.66 and a $\eta$ of $6.78 \%$ measured. Apparently, the dramatically enhanced cell performance of $\mathrm{S}-\mathrm{Co}_{3} \mathrm{O}_{4}$ nanowires can be directly ascribed to the introduced sulfur dopants into the $\mathrm{Co}_{3} \mathrm{O}_{4}$ structure, which enriches the electrocatalytically active sites on the surface (improvement in $J_{S C}$ ) and reduces the charge transfer resistance at the electrode/electrolyte interface (improvement in $F F$ ) [53]. The photovoltaic parameters of the DSSC with commercial Pt CE are measured $0.71 \mathrm{~V}$ for $V_{O C}$, $18.02 \mathrm{~mA} / \mathrm{cm}^{2}$ for $J_{S C}, 0.61$ for $F F$, and $7.28 \%$ for $\eta$, respectively. The superior performance of the DSSC with a Pt-CE over that with a $\mathrm{S}-\mathrm{Co}_{3} \mathrm{O}_{4} \mathrm{CE}$ can be attributed to a higher $J_{S C}$, justifying Pt's excellent electrocatalytic activity as benchmark material. However, it is noteworthy that the DSSC with $\mathrm{S}_{-} \mathrm{Co}_{3} \mathrm{O}_{4} \mathrm{CE}$ shows higher $F F$ values than that of the DSSC with Pt-CE. This indicates a lower electrochemical impedance which could be linked to the particle-packed, tip-joined nanowire structure (see EIS data below).

Cyclic voltammetry (CV) measurements in iodide/triiodide electrolyte were carried out to investigate the electrochemical properties of CEs. It can be seen in Fig. $5 \mathrm{~b}$ that $\mathrm{CV}$ curves of both $\mathrm{S}-\mathrm{Co}_{3} \mathrm{O}_{4}$ nanowires and $\mathrm{Pt}$ show two pairs of oxidation and reduction peaks in the potential range from -0.4 to $1.2 \mathrm{~V}$ vs. $\mathrm{Ag} / \mathrm{AgCl}$ reference electrode. The redox pair at more negative potentials is represented by Red-1 and Ox-1, which is attributed to the reaction of $\mathrm{I}_{3}{ }^{-}$ $+2 \mathrm{e}^{-} \rightarrow 3 \mathrm{I}^{-}$that dominantly occurs in the DSSCs device, whereas Red-2 and Ox-2 correspond 
to the other redox pair at more positive potentials contributed by the reaction $3 \mathrm{I}_{2}+2 \mathrm{e}^{-} \rightarrow 2 \mathrm{I}_{3}{ }^{-}$.

No obvious redox peak was observed in $\mathrm{CV}$ curve of $\mathrm{Co}_{3} \mathrm{O}_{4} \mathrm{CEs}$ at the negative potentials, indicating its poor electrocatalytic activity toward IRR. Notably, the introduced sulfur dopants in $\mathrm{Co}_{3} \mathrm{O}_{4}$ significantly enhances the electrocatalytic activity towards IRR. Moreover, separation of Red-1 peak and Ox-1 peak $\left(E_{p p}\right)$ is another key indicator to intrinsically compare the electrocatalytic activities. A smaller $E_{p p}$ indicates a better electrocatalytic activity towards the redox reaction. Fig. $5 \mathrm{~b}$ shows the $\mathrm{CV}$ of the $\mathrm{S}-\mathrm{Co}_{3} \mathrm{O}_{4}$ nanowire $\mathrm{CE}$ with a smaller $E_{p p}$ value compared to the Pt CEs further confirming its excellent electrocatalytic activity.

Tafel polarization curves are collected to further verify the electrocatalytic activities of CEs for DSSCs (Fig. 5c). The horizontal section of the curve can be attributed to the diffusion zone whilst the region with sharp slope can be attributed to the Tafel zone [24]. The limiting diffusion current density $\left(\boldsymbol{J}_{\text {lim }}\right)$ is defined as the intersection of the cathodic branch with the Y-axis. In addition, the intersection of the cathodic branch with the potential equilibrium line can be considered as the exchange current density $\left(J_{o}\right)$ [24]. A larger $J_{o}$ implies a better electrocatalytic activity. The Tafel polarization curve of the $\mathrm{S}_{-} \mathrm{Co}_{3} \mathrm{O}_{4}$ film shown higher $J_{o}$ than that of Pt which can be attributed to the much higher surface areas of the nanowire film. Also, the tendency of the $J_{o}$ agrees with that of the peak current density in CV curves (Fig. 5b) and DSSCs photovoltaic parameters (Fig. 5a).

To gain further insight into electrocatalytic reaction on $\mathrm{CE} / \mathrm{electrolyte}$ interface, electrochemical impedance spectra (EIS) were measured using a symmetric cell setup. Nyquist plots were illustrated in Fig. 5d, in which the semicircle corresponds to the catalytic charge-transfer process occurring at electrode-electrolyte interface and the diameter of the semicircle represents the charge transfer resistance. In particular, the high-frequency intercept on the real axis corresponds to the Ohmic series resistance $\left(R_{S}\right)$, which includes the sheet 
resistance of two identical electrodes and the resistance of electrolyte. The span of a single semi-circle along the real axis from high to low frequency represents the charge-transfer resistance $\left(R_{c t}\right)$ for the IRR at the electrode/electrolyte interface [51]. The $R_{s}$ and $R_{c t}$ data are summarized in Table 1. In an electrochemical reaction, a smaller diameter of the semicircle generally indicates a lower electrochemical reaction resistance with a faster electron transfer rate. As spinel $\mathrm{Co}_{3} \mathrm{O}_{4}$ is a semiconductor with high impedance, lower charge carrier mobility and few electrocatalytic sites compared with $\mathrm{Pt}$, the electron transfer is limited leading to a significantly large $R_{c t}$. However, the $R_{c t}$ is dramatically decreased with sulfur dopants that create excellent sites for IRR [48]. These impedance results are consistent with the obtained CV curves and Tafel polarization curves.

\subsection{Effects of film structure and VPH temperature on electrocatalytic performance}

The above results have validated that the electrocatalytically active sites in the spinel $\mathrm{Co}_{3} \mathrm{O}_{4}$ nanowire film could be readily created via a facile VPH sulfur doping technique. To further investigate the structure-performance relationship, the structural and electrochemical properties of resultant $\mathrm{S}_{-} \mathrm{Co}_{3} \mathrm{O}_{4}$ films have been systematically studied. The first subject under investigation is the microstructure as it plays an important role in providing a large surface area for active site creation and also efficient charge transports. Fig.6 (a) shows the $J$ $V$ curves of the DSSCs assembled with $\mathrm{S}-\mathrm{Co}_{3} \mathrm{O}_{4} \mathrm{CEs}$, which were prepared in $3 \mathrm{~h}, 5 \mathrm{~h}$, and $6 \mathrm{~h}$ chemical bath deposition, respectively, followed by identical VPH doping treatment. It is evident that the duration of chemical bath deposition strongly affects the electrocatalytic activities that lead to different $\eta$ (Table 1). The $J_{s c}$ values measured with different CEs are in the order: $\mathrm{S}_{-} \mathrm{Co}_{3} \mathrm{O}_{4}-4$ (6h deposition) $<\mathrm{S}_{-}-\mathrm{Co}_{3} \mathrm{O}_{4}-3(3 \mathrm{~h}$ deposition $) \approx \mathrm{S}-\mathrm{Co}_{3} \mathrm{O}_{4}-1(5 \mathrm{~h}$ deposition) $<\mathrm{S}-\mathrm{Co}_{3} \mathrm{O}_{4}-2$ (best performing sample, 4 h deposition). The decrease in $J_{s c}$ for the samples with longest deposition time (i.e., S- $\mathrm{Co}_{3} \mathrm{O}_{4}-4$ vs. $\mathrm{S}-\mathrm{Co}_{3} \mathrm{O}_{4}-3$ ) indicates a loss of effective electrocatalytically active surface. Moreover, the drops in $V_{o c}(0.68 \mathrm{~V} \rightarrow 0.63 \mathrm{~V})$ 
and $F F(0.60 \rightarrow 0.42)$ have also been observed in the film with extended deposition time (S$\mathrm{Co}_{3} \mathrm{O}_{4}-3$ vs. S- $\left.\mathrm{Co}_{3} \mathrm{O}_{4}-4\right)$ leading to a significant deterioration in $\eta(5.02 \% \rightarrow 1.40 \%)$. To further understand the electrochemical properties, EIS spectra of these $\mathrm{S}_{-} \mathrm{Co}_{3} \mathrm{O}_{4}$ CEs were measured (Fig. 6b and Table 1). It is evident that the $R_{s}$ value is reduced with a longer chemical deposition time (i.e., 4 h vs. 3 h) however excessive deposition leads to a drop in $R_{c t}$ : the $\mathrm{S}-\mathrm{Co}_{3} \mathrm{O}_{4}-4$ sample manifests a smallest $R_{s}$ value $(10.80 \Omega)$ and a largest $R_{c t}$ value $(10.102$ $\Omega)$. Consistent with the $J-V$ curves and EIS results, the Tafel polarization curves of the S$\mathrm{Co}_{3} \mathrm{O}_{4}-4$ sample demonstrate a lowest $J_{o}$ compared to others (Fig. 6c). Fig. 7a-c show the SEM images of the $\mathrm{S}_{-} \mathrm{Co}_{3} \mathrm{O}_{4}$ samples prepared with 3, 4 and 5 hours chemical deposition. The nanowire array structures have been obtained with increased thickness $(1.5,3$ and $4 \mu \mathrm{m}$ for 3, 4 and 5 hours samples respectively) while prolonged deposition (i.e., 6h) will generate micron-scaled aggregates (SEM not shown herein) onto the nanowire array layer. Notably, cracks tended to be formed within the thicker $\mathrm{Co}_{3} \mathrm{O}_{4}$ films, i.e., > 5 hour chemical deposition, which is probably due to the mechanical strain accumulation upon the increased film thickness or the formation of sulfur during the VPH treatment (see results from VPH duration experiments below). It is reasonable to attribute the superior electrocatalytic performance of S- $-\mathrm{Co}_{3} \mathrm{O}_{4}$ samples prepared with optimal chemical deposition $(4 \mathrm{~h})$ to the enrichment of the active surface, while the impaired electrocatalytic performance of thicker film (chemical bath for $>4 \mathrm{~h}$ ) is due to the disadvantageous electron transfer that could be linked to the structural deformation/film disconnection from the FTO substrate.

It is believed that thermal energy provided in the VPH treatment essentially drives the interaction between the pristine $\mathrm{Co}_{3} \mathrm{O}_{4}$ crystals and the $\mathrm{H}_{2} \mathrm{~S}$ gas. Thus, the VPH temperature is the second aspect of our investigation. The VPH treatments of the $\mathrm{Co}_{3} \mathrm{O}_{4}$ nanowire films (with optimal thickness, chemical bath deposited for 4 hours) at different temperatures for $6 \mathrm{~h}$ have been implemented, and the resultant structures are shown in Fig. 8. It is evident that the 
VPH treatment at all temperatures $\left(70-180^{\circ} \mathrm{C}\right)$ did not significantly change the nanowire morphologies. We trust that $6 \mathrm{~h} \mathrm{VPH}$ treatment is sufficient to allow full doping process at given temperatures (see below for reaction duration comparison results). In good agreement with the TEM images in Fig. 3, the TEM images of the individual samples (insets in Fig. 8) unanimously shown that the nanowires are consist of polycrystalline interconnected $\mathrm{Co}_{3} \mathrm{O}_{4}$ nanocrystals with sizes of a few tens of $\mathrm{nm}$. More importantly, the SAED of the nanowires manifest similar diffraction patterns that could be ascribed to (111), (220), (311), (400), (422), (511) and (440) crystal planes of spinel $\mathrm{Co}_{3} \mathrm{O}_{4}$. No formation of $\mathrm{Co}_{3} \mathrm{~S}_{4}$ crystal has been detected in our samples. It is noteworthy that the films treated at higher temperature, i.e., 150, $180^{\circ} \mathrm{C}$ partly peeled off from the FTO substrates (SEM not shown). This observation implies the promoted interaction of the moisture with the $\mathrm{Co}_{3} \mathrm{O}_{4}$ film or the enhanced formation of sulfur during the VPH treatment may be detrimental to film integrity and thereby the electrical conductivity (between adjacent nanoparticles and/or between the $\mathrm{S}_{-} \mathrm{Co}_{3} \mathrm{O}_{4}$ films and the FTO substrates). Although there was no significant morphology change observed between $70^{\circ} \mathrm{C}$ to $120^{\circ} \mathrm{C}$, the reaction temperature has significant impacts on the photovoltaic performance of CEs for DSSCs. As shown in the $J$ - $V$ curves in Fig. 9a and Table 1, DSSCs equipped with CEs prepared at $70{ }^{\circ} \mathrm{C}$ renders similar $V_{O C}, F F$, but smaller $J_{S C}$ compared to those with CEs obtained at $90{ }^{\circ} \mathrm{C}$ (best performing CE, Fig. 5a), probably due to less amount of the electrocatalytically active sites created at a lower temperature. This trend is in good agreement with the lower current density of the reduction peak current at CV curve (Fig. 9b), lower $J_{0}$ in Tafel polarization curve (Fig. 9c) and larger $R_{c t}$ in EIS data (Fig. 9d). Further increase in temperature (i.e., $120^{\circ} \mathrm{C}$ ) will lead to an inferior electrocatalytic performance, i.e., a reduced $J_{S C}, F F$ in $J$ - $V$ curve, a decreased reduction peak current in CV curve, a reduced $J_{o}$ and significantly increased $R_{c t}$. These results point clearly to an obvious impairment in electrocatalytic performance that could be due to the aforementioned structural deformation 
at higher temperatures. An even poorer performance of the DSSCs equipped with CE prepared at a higher temperature (Fig. 9, Table 1), i.e., $150^{\circ} \mathrm{C}$, matched the expected tendency and justified our hypothesis.

\subsection{Sulfur dopant variation and its correlation with electrocatalytic performance}

After determining the optimal VPH temperature, the VPH treatments with different durations (15 minutes to 12 hours) have been performed to investigate the detailed doping process. Fig. 10a shows the XRD data of the samples after VPH treatment without $\mathrm{CS}_{2}$ rinsing. It is evident that a diffraction pattern of spinel $\mathrm{Co}_{3} \mathrm{O}_{4}$ crystal phase has been detected after $12 \mathrm{~h}$ VPH treatment indicating that the bulk $\mathrm{Co}_{3} \mathrm{O}_{4}$ nanowire crystal structure is unaltered after VPH treatment. Evidently, a number of diffraction peaks at low angle range, i.e., $2 \theta<40^{\circ}$, appeared after a short period of $\mathrm{VPH}$ treatment at $90^{\circ} \mathrm{C}$. These peaks can be attributed to the elemental sulfur that gradually formed and enriched as VPH treatment proceeded. Consistent with the XRD sample, the Raman spectra of the samples obtained after 1 hour and 9 hours VPH treatment (with $\mathrm{CS}_{2}$ rinsing) show almost identical peaks ascribable to spinel $\mathrm{Co}_{3} \mathrm{O}_{4}$ crystal. The extents of red shifts of the peaks of both samples with respect to the pristine $\mathrm{Co}_{3} \mathrm{O}_{4}$ crystal (Fig. 2b, dashed line in Fig. 10) are similar, indicating a rapid VPH doping process. Interestingly, VPH treatment at a higher temperature for the same durations tended to generate more amount of sulfur, as the XRD data shown in Fig. 10c. An SEM image of the $\mathrm{S}-\mathrm{Co}_{3} \mathrm{O}_{4}$ samples after VPH treatment without $\mathrm{CS}_{2}$ rinsing shows the formation of sulfur can be found within the nanowire networks. This results could partly rationalize the deteriorated electrocatalytic performance of the CEs prepared at higher temperature: the dominant inter-growth of bulky sulfur within the $\mathrm{Co}_{3} \mathrm{O}_{4}$ nanowires with pores may undermine the nanowire structural stability, probably via creating elastic stress (considering the different dimensional properties and thermal expansions of $\mathrm{Co}_{3} \mathrm{O}_{4}$ and sulfur crystals under heating and cooling processes during VPH treatment) [52]. 
The surface chemical information of resultant $\mathrm{S}-\mathrm{Co}_{3} \mathrm{O}_{4}$ samples obtained with different

VPH treatment durations has been characterized with XPS. The data of three typical samples

(prepared in 30 minutes, 3 hours and 9 hours) are shown in Fig. 11. The survey scan data

confirmed that the existence of cobalt, oxygen, carbon and sulfur elements in all samples and the sulfur peak appeared after $30 \mathrm{~min}$ VPH treatment (Fig. 11a). In the high-resolution Co $2 p$ spectra (Fig. 11b), the shifting of the Co $2 \mathrm{p}_{3 / 2}$ peaks of all $\mathrm{S}-\mathrm{Co}_{3} \mathrm{O}_{4}$ samples with regards to pristine $\mathrm{Co}_{3} \mathrm{O}_{4}$ sample has been evident and the extent of shifting in the samples prepared with longer VPH treatment $(3 \mathrm{~h}, 9 \mathrm{~h})$ is more obvious indicating that a further change of the chemical environment of Co upon the sulfur doping. Consistently, in the O 1s spectra of $\mathrm{S}-\mathrm{Co}_{3} \mathrm{O}_{4}$ sample (Fig. 11c), the lattice oxygen $\left(\mathrm{O}_{\text {lat }}\right)$ peak centered at $530.0 \mathrm{eV}$ has been rapidly weakened (after 30 minute VPH treatment) compared to the pristine $\mathrm{Co}_{3} \mathrm{O}_{4}$ sample (Fig. 4c) confirming an effective substitution of surface oxygen with sulfur dopant atoms. Furthermore, the $\mathrm{S} 2 \mathrm{p}_{3 / 2}$ peaks of $\mathrm{S}_{-} \mathrm{Co}_{3} \mathrm{O}_{4}$ samples verified the presence of sulfide $\left(\mathrm{S}^{2-}\right)$, polysulfide $\left(\mathrm{S}_{\mathrm{n}}{ }^{2-}\right)$, and a trace amount of sulfite $\left(\mathrm{SO}_{3}{ }^{2-}\right)$, sulfate species $\left(\mathrm{SO}_{4}{ }^{2-}\right)$ (Fig. 11d).

The electrocatalytic performance of the CEs prepared with varied VPH treatment duration has been tested. As the CV curve shown in Fig. 12a, two pairs of the redox peaks for the triiodide redox reactions appeared after 15 minutes VPH treatment further justifying a rapid and effective doping of the sulfur into the $\mathrm{Co}_{3} \mathrm{O}_{4}$ crystal. This is followed by a gradual increase in the redox peak current densities and also decrease in $E_{p p}$. After about $6 \mathrm{~h} \mathrm{VPH}$ treatment, the CV curve obtained with the CEs become similar, and further VPH treatment did not increase the current densities or reduce the $E_{p p}$ signifying the completion of the sulfur doping process. This trend is in good agreement with the Tafel polarization curve of the CEs, showing an improving $J_{o}$ before 6 hour and apparent drop for the samples prepared in 9 and 
the CEs rapidly reduces from about $15 \Omega \mathrm{cm}^{2}$ to less than $2 \Omega \mathrm{cm}^{2}$ as the VPH treatment progressed from 15 minutes to about 2 hours. The value of the CEs prepared from VPH treatment for 12 hours has increased indicating a slightly deteriorated electrocatalytic performance. The photovoltaic performance of the DSSCs equipped with the CEs prepared in 3, 6, 9 and $12 \mathrm{~h}$ VPH treatment (Fig. 5a, 12d, Table 1) showed an increase in $\eta$ of the CEs prepared at $6 \mathrm{~h}$ and decrease after the VPH treatment is prolonged. The loss of efficiency is mainly due to a drop in $J_{s c}$ implying the decrease in available electrocatalytically active sites which can be linked to the structural instability originated from the sulfur gain formation within the nanowire film. These results are in good alignment with the XRD data (Fig. 10) and electrochemical characterizations of the CEs (Fig. 12 a-c).

Although anion dope $\mathrm{Co}_{3} \mathrm{O}_{4}$ crystals are capable of catalyzing multiple useful reactions $[38,40,46,47]$, the direct linkage of their catalytic activities to the dopant levels has not been reported. Herein, we attempted to correspond the sulfur dopant concentrations to a few key indicators of their electrocatalytic activities, i.e., the $E_{p p}, R_{c t}$ and $J_{0}$ extracted from $\mathrm{CV}$ curve, Nyquist plots in EIS and Tafel polarization curve, respectively. As the correlation figure schematically shown in Fig. 13, these key indicators varied consistently with the sulfur dopant level as the VPH treatment proceeds. The overall VPH doping process could be divided according to the alteration tendency: at the first stage $(0-2 \mathrm{~h})$, the surface doping process occurs in a rapid manner leading a rigorous increase in sulfur dopant concentration on the surface, in the meantime, the electrocatalytic activities towards IRR dramatically improve (increase in $J_{0}$, decrease in $E_{p p}$ and $R_{c t}$ ). This is followed by the second stage (2-6h) where the substitutable oxygen atoms have been almost entirely substituted with sulfur atoms under VPH conditions leading to a constant surface sulfur dopant concentration and also electrocatalytic activities. The effectiveness of the in-situ surface VPH doping approach can be reflected by the extraordinarily high dopant level on the surface even at mild temperature 
$398\left(90^{\circ} \mathrm{C}\right)$ and relatively short period of time (2 hours). Given the elemental sulfur formed within the $\mathrm{S}-\mathrm{Co}_{3} \mathrm{O}_{4}$ film, the prolong reaction (6h onwards) leads to a deteriorated film structure and thereby the electrocatalytic activities. However, we believe that this declination in structural

401

402 stability and electrocatalytic performance could be totally avoided by choosing other substrates on which the sulfur formation is largely suppressed.

\section{Conclusions}

In summary, we demonstrate a facile VPH approach to effectively dope the $\mathrm{Co}_{3} \mathrm{O}_{4}$ nanowire to create surface active sulfur species that is capable of electrocatalyzing the iodine reduction reaction. The DSSCs equipped with $\mathrm{S}_{-} \mathrm{Co}_{3} \mathrm{O}_{4}$ nanowires film counter electrode (CE) demonstrate significantly improved electrocatalytic activities leading to a best energy conversion efficiency of $6.78 \%$, which is comparable to those of DSSCs with commercial Pt CEs (7.36\%). Moreover, the impacts of chemical bath durations, VPH temperature and VPH duration on the electrocatalytic activities have been systematically investigated. Our structural and electrochemical characterization results allude to the importance of achieving balanced properties: a larger surface area to allow completed sulfur doping and a stable structure resulted from optimal VPH treatment for efficient charge transfer. More importantly, the doping processes have been carefully investigated by monitoring the variation of the surface chemical species under VPH conditions. Our results have unambiguously revealed for the first time a close correlation between the surface sulfur dopant and the key electrocatalytic activity indicators. The demonstrated findings provide insights into the VPH doping processes that could be utilized to effectively unlock the catalytic potentials of lowcost, earch-abundant metal oxide crystals as high-performance catalysts for energy conversion and storage applications. 


\section{Acknowledgements}

424

Authors acknowledge the financial support by The Australian Research Council

(DE170100607) and technical assistance by the Centre for Microscopy and Microanalysis (CMM), the University of Queensland.

427

428

\section{References}

429

430

[1] M. Grätzel, J. Photochem. Photobiol., C, 4 (2003) 145-153.

431

[2] A. Hagfeldt, G. Boschloo, L. Sun, L. Kloo, H. Pettersson, Chem. Rev., 110 (2010) 6595-

432 6663.

433

[3] S. Mathew, A. Yella, P. Gao, R. Humphry-Baker, B.F.E. Curchod, N. Ashari-Astani, I. 434 Tavernelli, U. Rothlisberger, M.K. Nazeeruddin, M. Grätzel, Nat. Chem., 6 (2014) 242.

[4] K. Kakiage, Y. Aoyama, T. Yano, K. Oya, J.-i. Fujisawa, M. Hanaya, Chem. Commun., 51 (2015) 15894-15897.

[5] M. Ye, X. Wen, M. Wang, J. Iocozzia, N. Zhang, C. Lin, Z. Lin, Mater. Today, 18 (2015) $155-162$.

439

[6] S. Thomas, T.G. Deepak, G.S. Anjusree, T.A. Arun, S.V. Nair, A.S. Nair, J. Mater. Chem.

A, 2 (2014) 4474-4490.

441

[7] L. Wang, M. Al-Mamun, P. Liu, Y. Wang, H.G. Yang, H.F. Wang, H. Zhao, NPG Asia

442 Mater., 7 (2015) e226.

443

[8] J.D. Roy-Mayhew, D.J. Bozym, C. Punckt, I.A. Aksay, ACS Nano, 4 (2010) 6203-6211.

444

[9] R. Kumar, P. Bhargava, J. Alloys Compd., 748 (2018) 905-910.

445

[10] Q. Li, J. Wu, Q. Tang, Z. Lan, P. Li, J. Lin, L. Fan, Electrochem. Commun., 10 (2008) 
447

448

449

450

451

452

453

454

455

456

457

458

459

460

461

462

463

464

465

466

467

468

469

470

471

[11] J. Wu, Q. Li, L. Fan, Z. Lan, P. Li, J. Lin, S. Hao, J. Power Sources, 181 (2008) 172-176.

[12] H. Yu, C.Z. Peng, W. Dong, Z. Bo, Y. Shuang, W.H. Feng, H. P., Z.H. Jun, Y.H. Gui, Small, 10 (2014) 484-492.

[13] B. Zhang, N.N. Zhang, J.F. Chen, Y. Hou, S. Yang, J.W. Guo, X.H. Yang, J.H. Zhong, H.F. Wang, P. Hu, H.J. Zhao, H.G. Yang, Sci. Rep., 3 (2013) 3109.

[14] L. Cheng, Y. Hou, B. Zhang, S. Yang, J.W. Guo, L. Wu, H.G. Yang, Chem. Commun., 49 (2013) 5945-5947.

[15] L. Yi, Y. Liu, N. Yang, Z. Tang, H. Zhao, G. Ma, Z. Su, D. Wang, Energ. Environ. Sci., $6(2013) 835-840$.

[16] X. Wang, Y. Xie, Z. Cai, N. Xiong, Z. Xu, M. Li, Q. Feng, W. Zhou, K. Pan, J. Alloys Compd., 739 (2018) 568-576.

[17] Y. Xie, C. Zhang, G. Yang, J. Yang, X. Zhou, J. Ma, J. Alloys Compd., 696 (2017) 938946.

[18] H. Wu, Y. Wang, L. Zhang, Z. Chen, C. Wang, S. Fan, J. Alloys Compd., 745 (2018) $222-227$.

[19] H. Che, X. Liu, Y. Gao, J. Liu, Z. Cao, J. Alloys Compd., 705 (2017) 645-651.

[20] L. Guo-ran, W. Feng, J. Qi-wei, G. Xue-ping, S. Pan-wen, Angew. Chem., Int. Ed., 49 (2010) 3653-3656.

[21] G.R. Li, J. Song, G.L. Pan, X.P. Gao, Energ. Environ. Sci., 4 (2011) 1680-1683.

[22] W. Mingxing, L. Xiao, H. Anders, M. Tingli, Angew. Chem., Int. Ed., 50 (2011) 35203524.

[23] M. Wu, X. Lin, Y. Wang, L. Wang, W. Guo, D. Qi, X. Peng, A. Hagfeldt, M. Grätzel, T. Ma, J. Am. Chem. Soc., 134 (2012) 3419-3428.

[24] Y. Hou, D. Wang, X.H. Yang, W.Q. Fang, B. Zhang, H.F. Wang, G.Z. Lu, P. Hu, H.J. Zhao, H.G. Yang, Nat. Commun., 4 (2013) 1583. 
472

473

474

475

476

477

478

479

480

481

482

483

484

485

486

487

488

489

490

491

492

493

494

495

496

[25] J. Zhang, S. Najmaei, H. Lin, J. Lou, Nanoscale, 6 (2014) 5279-5283.

[26] G. Nagaraju, J.H. Lim, S.M. Cha, J.S. Yu, J. Alloys Compd., 693 (2017) 1297-1304.

[27] C. Bao, H. Huang, J. Yang, H. Gao, T. Yu, J. Liu, Y. Zhou, Z. Li, Z. Zou, Nanoscale, 5 (2013) 4951-4957.

[28] Y. Jiang, X. Zhang, Q.Q. Ge, B.B. Yu, Y.G. Zou, W.J. Jiang, W.G. Song, L.J. Wan, J.S. Hu, Nano Lett., 14 (2014) 365-372.

[29] S. Yun, H. Zhang, H. Pu, J. Chen, A. Hagfeldt, T. Ma, Adv. Energy Mater., 3 (2013) $1407-1412$.

[30] C.-H. Lin, C.-H. Tsai, F.-G. Tseng, C.-C.M. Ma, H.-C. Wu, C.-K. Hsieh, J. Alloys Compd., 692 (2017) 941-949.

[31] G.H. Guai, M.Y. Leiw, C.M. Ng, C.M. Li, Adv. Energy Mater., 2 (2012) 334-338.

[32] S.-F. Wang, K.K. Rao, T.C.K. Yang, H.-P. Wang, J. Alloys Compd., 509 (2011) 19691974.

[33] M. Wu, T. Ma, J. Phys. Chem. C, 118 (2014) 16727-16742.

[34] D. Yu, E. Nagelli, F. Du, L. Dai, J. Phys. Chem. Lett., 1 (2010) 2165-2173.

[35] D.K. Hwang, D. Song, S.S. Jeon, T.H. Han, Y.S. Kang, S.S. Im, J. Mater. Chem. A, 2 (2014) 859.

[36] B.-M. Kim, M.-K. Son, S.-K. Kim, N.-Y. Hong, S. Park, M.-S. Jeong, H. Seo, K. Prabakar, H.-J. Kim, Electrochim. Acta, 117 (2014) 92-98.

[37] H. Sun, H.M. Ang, M.O. Tade, S. Wang, J. Mater. Chem. A, 1 (2013) 14427-14442.

[38] H. Yu, Y. Li, X. Li, L. Fan, S. Yang, Chem. -Eur. J., 20 (2014) 3457-3462.

[39] Z. Mei, Z. Shen, W. Wang, Y. Zhang, Environ. Sci. Technol., 42 (2007) 590-595.

[40] A. Gasparotto, D. Barreca, D. Bekermann, A. Devi, R.A. Fischer, P. Fornasiero, V.

Gombac, O.I. Lebedev, C. Maccato, T. Montini, G. Van Tendeloo, E. Tondello, J. Am. Chem. Soc., 133 (2011) 19362-19365. 
[41] P. Liu, H. Zhang, H. Liu, Y. Wang, T. An, W. Cai, H. Yang, X. Yao, G. Zhu, R. Webb,

498

499

500

501

502

503

504

505

506

507

508

509

510

511

512

513

514

515

516

517

518

519
H. Zhao, Small, 9 (2013) 3043-3050.

[42] P. Liu, H. Zhang, H. Liu, Y. Wang, X. Yao, G. Zhu, S. Zhang, H. Zhao, J. Am. Chem. Soc., 133 (2011) 19032-19035.

[43] V.G. Hadjiev, M.N. Iliev, I.V. Vergilov, J. Phys. C.: Solid State Phys., 21 (1988) L199.

[44] I. Lorite, J.J. Romero, J.F. Fernández, J. Raman Spectrosc., 43 (2012) 1443-1448.

[45] S. Lu, Y. Wang, F. Li, G. Yang, H. Yang, X. Zhang, Y. Liu, The Journal of Physical Chemistry C, 121 (2017) 12524-12530.

[46] Y. Minghao, W. Zhengke, H. Cheng, W. Zilong, L. Chaolun, Z. Cunyuan, T. Yexiang, L. Xihong, Y. Shihe, Adv. Mater., 29 (2017) 1602868.

[47] Z. Wang, H. Liu, R. Ge, X. Ren, J. Ren, D. Yang, L. Zhang, X. Sun, ACS Catal., 8 (2018) 2236-2241.

[48] Z. Tan, P. Liu, H. Zhang, Y. Wang, M. Al-Mamun, H.G. Yang, D. Wang, Z. Tang, H. Zhao, Chem. Commun., 51 (2015) 5695-5697.

[49] M. Al-Mamun, H. Zhang, P. Liu, Y. Wang, J. Cao, H. Zhao, RSC Adv., (2014).

[50] Y. Li, H. Wang, H. Zhang, P. Liu, Y. Wang, W. Fang, H. Yang, Y. Li, H. Zhao, Chem. Commun., 50 (2014) 5569-5571.

[51] H. Bi, W. Zhao, S. Sun, H. Cui, T. Lin, F. Huang, X. Xie, M. Jiang, Carbon, 61 (2013) 116-123.

[52] M. Daniel, M. Friedemann, N. Jöhrmann, A. Liebig, J. Donges, M. Hietschold, G. Beddies, M. Albrecht, Phys. Status Solidi A, 210 (2013) 140-146. 
Table and Figure captions

521

522 Table 1 Photovoltaic parameters of the DSSCs with the $\mathrm{Co}_{3} \mathrm{O}_{4}, \mathrm{~S}-\mathrm{Co}_{3} \mathrm{O}_{4}$ and commercial $\mathrm{Pt}$ 523 counter electrodes.

524 Fig. 1 Schematic illustration of the VPH doping process.

525 Fig. 2 Crystal structure of the $\mathrm{Co}_{3} \mathrm{O}_{4}$ samples and $\mathrm{S}-\mathrm{Co}_{3} \mathrm{O}_{4}$ samples. (a) XRD pattern, and (b) 526 room-temperature Raman spectra.

527 Fig. 3 (a, e) SEM image, (b, f) TEM image, (c, g) electron diffraction and (d, h) HRTEM 528 image of $\mathrm{Co}_{3} \mathrm{O}_{4}$ and $\mathrm{S}-\mathrm{Co}_{3} \mathrm{O}_{4}$ samples, respectively.

529 Fig. 4 XPS spectra: (a) survey spectra, (b) $\mathrm{Co} 2 \mathrm{p}$, (c) $\mathrm{O} 1$ s spectra of $\mathrm{Co}_{3} \mathrm{O}_{4}$ and $\mathrm{S}^{-\mathrm{Co}_{3} \mathrm{O}_{4}}$ 530 samples, (d) $\mathrm{S} 2 \mathrm{p}$ spectrum of $\mathrm{S}-\mathrm{Co}_{3} \mathrm{O}_{4}$ sample.

531 Fig. 5 (a) $J$ - $V$ curve, (b) cyclic voltammograms, (c) Tafel polarization curves and (d) 532 electrochemical impedance spectroscopy obtained with the $\mathrm{Co}_{3} \mathrm{O}_{4}$ and $\mathrm{S}_{-}-\mathrm{Co}_{3} \mathrm{O}_{4}$ and 533 commercial Pt electrodes.

Fig. 6 (a) $J-V$ curve, (b) electrochemical impedance spectroscopy, (c) Tafel polarization curves of the $\mathrm{S}^{-} \mathrm{Co}_{3} \mathrm{O}_{4}$ samples with different thicknesses, via controlled chemical bath deposition durations $\left(3,5,6\right.$ h), i.e., $\mathrm{S}-\mathrm{Co}_{3} \mathrm{O}_{4}-1, \mathrm{~S}-\mathrm{Co}_{3} \mathrm{O}_{4}-3, \mathrm{~S}_{-} \mathrm{Co}_{3} \mathrm{O}_{4}-4$ samples.

537 Fig.7 (a-c) SEM images of the $\mathrm{S}-\mathrm{Co}_{3} \mathrm{O}_{4}$ samples prepared with chemical bath deposition durations of 3, 4, 5 h, respectively, i.e., $\mathrm{S}-\mathrm{Co}_{3} \mathrm{O}_{4}-1, \mathrm{~S}_{-}-\mathrm{Co}_{3} \mathrm{O}_{4}-2, \mathrm{~S}-\mathrm{Co}_{3} \mathrm{O}_{4}-3$ samples. Insets in (a-c) are the SEM images showing the surface morphologies at low magnifications and film thickness. 
541 Fig. 8 SEM images, TEM images and selected area electron diffraction patterns of the

542 samples prepared in VPH treatment for 6 hours at different temperatures: (a) 70, (b) 120, (c)

$543 \quad 150$ and (d) $180{ }^{\circ} \mathrm{C}$.

544 Fig. 9 (a) $J-V$ curve, (b) cyclic voltammograms, (c) Tafel polarization curves and (d)

545 electrochemical impedance spectroscopy obtained with $\mathrm{S}-\mathrm{Co}_{3} \mathrm{O}_{4}$ prepared with VPH 546 treatment at temperatures: 70,120 and $150^{\circ} \mathrm{C}$.

547 Fig. 10 (a) XRD data of the samples prepared after VPH treatments with different durations

548 without rinsing in $\mathrm{CS}_{2}$, (b) Raman spectra of the samples prepared 1 and $9 \mathrm{~h} \mathrm{VPH}$ treatment 549 with $\mathrm{CS}_{2}$ rinsing, (c) XRD data of the samples prepared after VPH with different 550 temperatures without rinsing in $\mathrm{CS}_{2}$, (d) SEM images of the sample showing the sulfur 551 generated in VPH treatment prior to $\mathrm{CS}_{2}$ rinsing.

552 Fig. 11 XPS spectra of the $\mathrm{Co}_{3} \mathrm{O}_{4}$ and $\mathrm{S}-\mathrm{Co}_{3} \mathrm{O}_{4}$ samples prepared with $30 \mathrm{~min}, 3 \mathrm{~h}$ and $9 \mathrm{~h}$

553 VPH treatment: (a) survey scan, (b) Co 2p, (c) O 1s and (d) S 2p spectra.

554 Fig. 12 (a) cyclic voltammograms, (b) Tafel polarization curves, (c) electrochemical 555 impedance spectroscopy data and (d) $J-V$ curves obtained with $\mathrm{S}_{-} \mathrm{Co}_{3} \mathrm{O}_{4}$ prepared with $\mathrm{VPH}$ 556 treatment at $90^{\circ} \mathrm{C}$ for varied durations.

557 Fig. 13 Variation of the sulfur dopant levels, redox peak-to-peak potential differences in 558 cyclic voltammograms, electrocatalytic charge transfer resistance and logarithmic current 559 density $(\log J)$ as a function of VPH treatment duration. 


\begin{tabular}{|c|c|c|c|c|c|c|c|c|c|}
\hline Sample & $\begin{array}{l}\text { Chemical } \\
\text { bath } \\
\text { durations } \\
\text { (h) }\end{array}$ & $\begin{array}{l}\text { VPH } \\
\text { Temper } \\
\text { ature } \\
\left({ }^{\circ} \mathrm{C}\right)\end{array}$ & $\begin{array}{l}\text { VPH } \\
\text { duratio } \\
\text { ns (h) }\end{array}$ & $\begin{array}{l}J_{S C} \\
\left(\mathbf{m A} / \mathbf{c m}^{2}\right)\end{array}$ & $\begin{array}{l}V_{O C} \\
(\mathbf{V})\end{array}$ & $F F$ & $\eta$ & $\boldsymbol{R}_{s}(\mathbf{\Omega})$ & $\begin{array}{l}R_{c t}(\Omega \\
\left.\mathbf{c m}^{2}\right)\end{array}$ \\
\hline $\mathrm{Co}_{3} \mathrm{O}_{4}$ & 4 & - & - & 3.43 & 0.57 & 0.11 & 0.21 & - & - \\
\hline $\mathrm{S}-\mathrm{Co}_{3} \mathrm{O}_{4}-1$ & 3 & 90 & 6 & 12.06 & 0.68 & 0.60 & 4.95 & 14.10 & 3.500 \\
\hline $\mathrm{S}-\mathrm{Co}_{3} \mathrm{O}_{4}-2$ & 4 & 90 & 6 & 15.03 & 0.68 & 0.66 & 6.78 & 12.61 & 0.564 \\
\hline $\mathrm{S}-\mathrm{Co}_{3} \mathrm{O}_{4}-3$ & 5 & 90 & 6 & 12.16 & 0.68 & 0.60 & 5.02 & 12.50 & 7.021 \\
\hline $\mathrm{S}-\mathrm{Co}_{3} \mathrm{O}_{4}-4$ & 6 & 90 & 6 & 5.32 & 0.63 & 0.42 & 1.40 & 10.80 & 10.102 \\
\hline $\mathrm{S}-\mathrm{Co}_{3} \mathrm{O}_{4}-5$ & 4 & 70 & 6 & 13.08 & 0.67 & 0.68 & 6.03 & 14.20 & 1.064 \\
\hline $\mathrm{S}-\mathrm{Co}_{3} \mathrm{O}_{4}-6$ & 4 & 120 & 6 & 10.01 & 0.68 & 0.50 & 3.44 & 15.72 & 8.037 \\
\hline $\mathrm{S}-\mathrm{Co}_{3} \mathrm{O}_{4}-7$ & 4 & 150 & 6 & 2.67 & 0.45 & 0.29 & 0.35 & 19.29 & 23.92 \\
\hline $\mathrm{S}-\mathrm{Co}_{3} \mathrm{O}_{4}-8$ & 4 & 90 & 3 & 12.74 & 0.69 & 0.65 & 5.67 & 12.25 & 1.393 \\
\hline $\mathrm{S}-\mathrm{Co}_{3} \mathrm{O}_{4}-9$ & 4 & 90 & 9 & 9.21 & 0.70 & 0.73 & 4.74 & 14.49 & 1.438 \\
\hline $\mathrm{S}-\mathrm{Co}_{3} \mathrm{O}_{4}-10$ & 4 & 90 & 12 & 5.91 & 0.70 & 0.69 & 2.84 & 15.05 & 1.948 \\
\hline $\mathrm{Pt}$ & - & - & - & 18.02 & 0.71 & 0.61 & 7.28 & 23.75 & 1.18 \\
\hline
\end{tabular}

562 


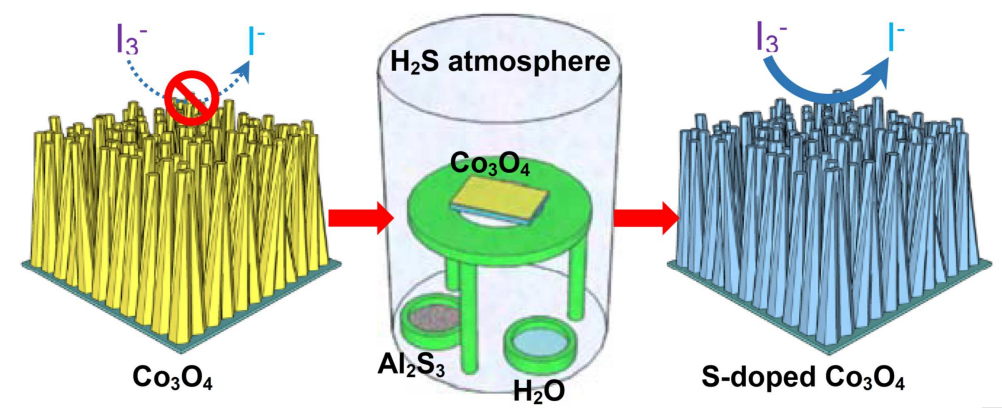

566

Fig. 1

567

568

569

570

571

572
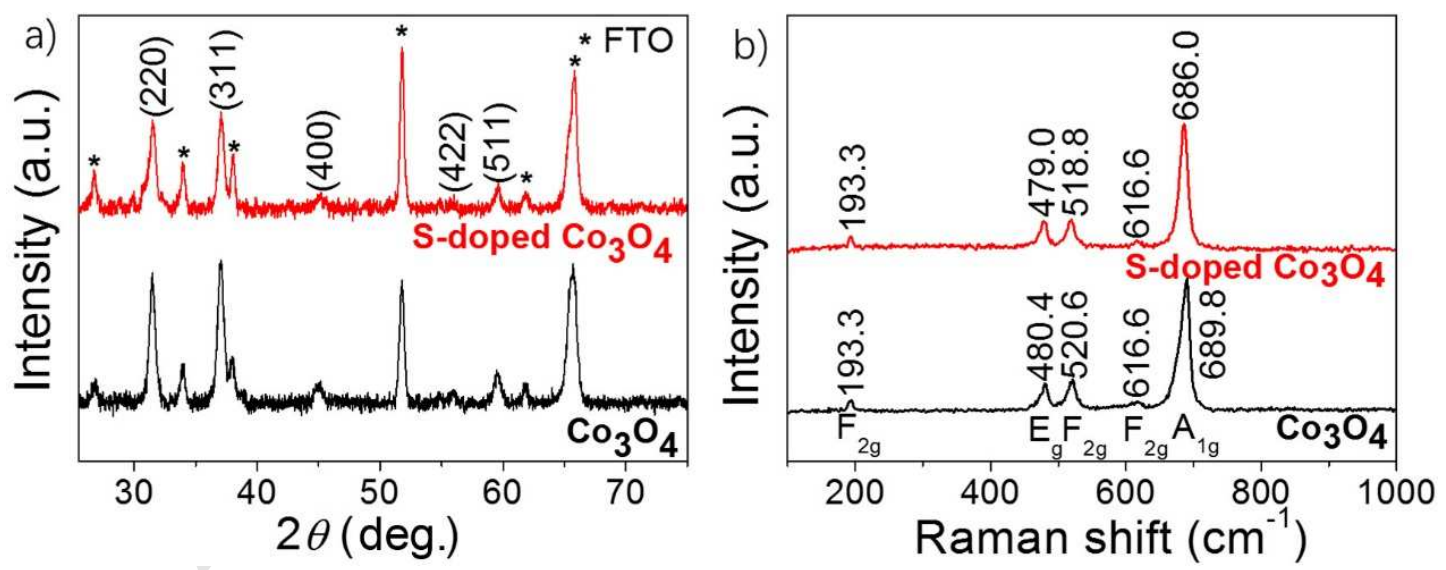

Fig. 2 


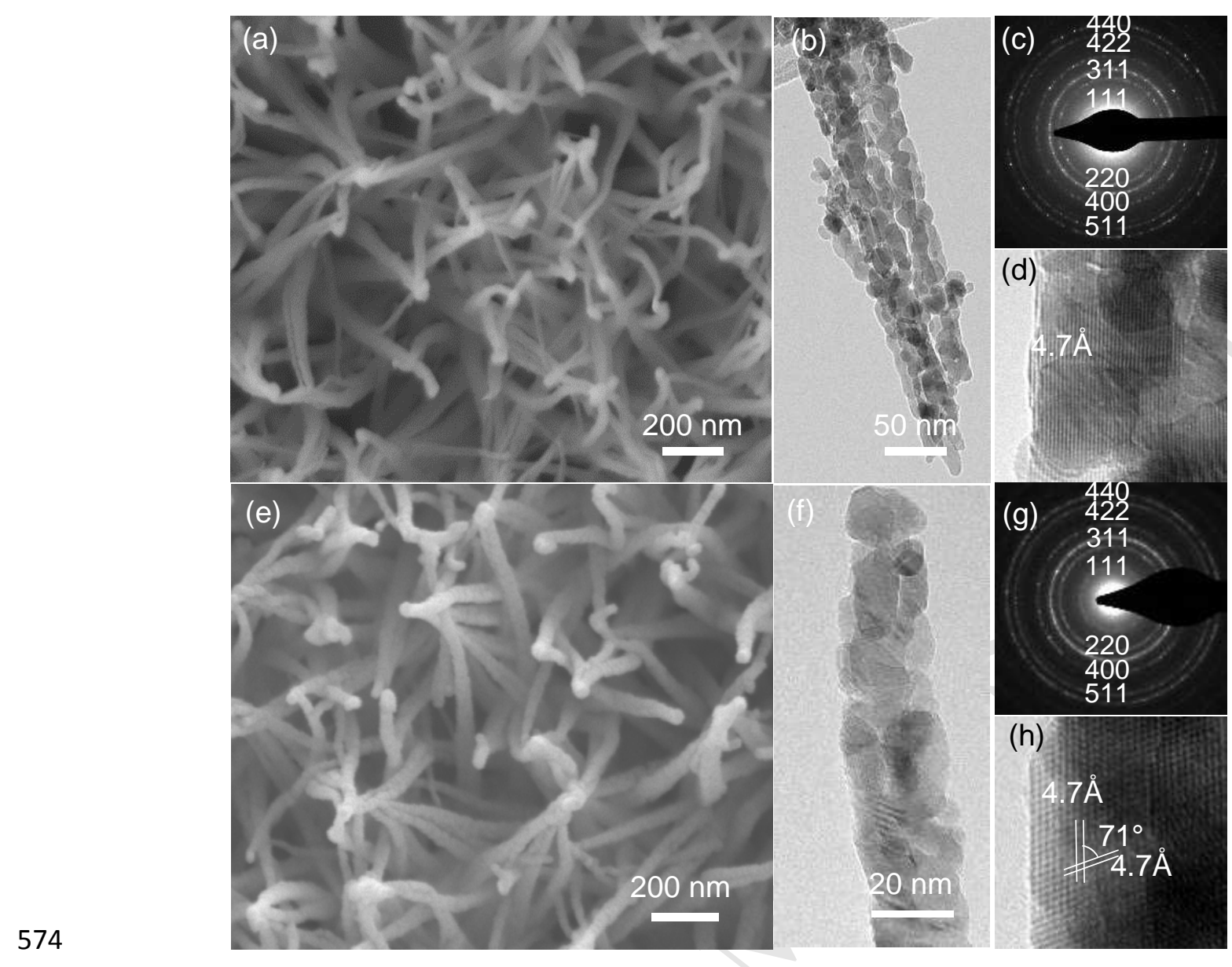

Fig. 3

576

577

578 

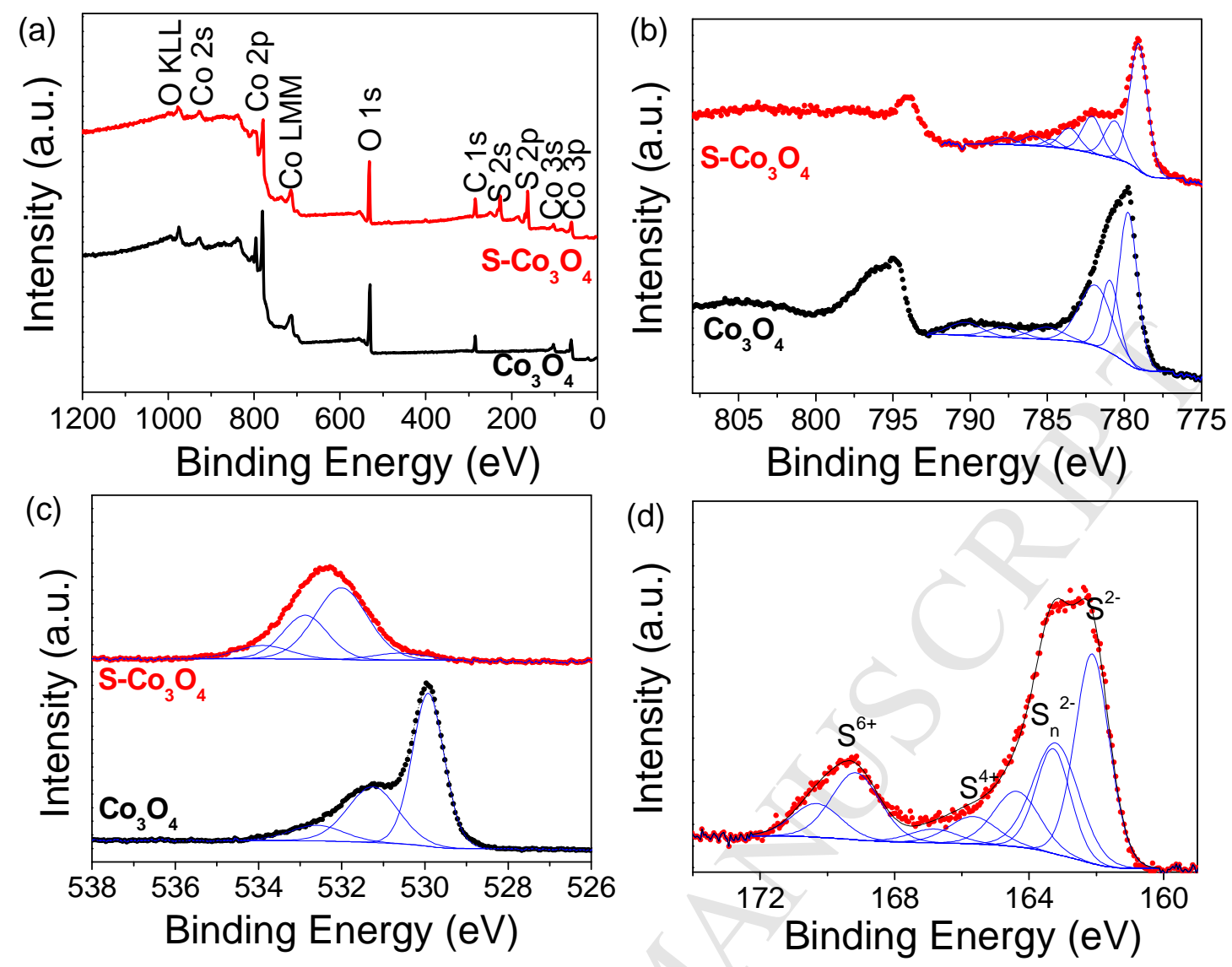

Fig. 4

581

582

583

584

585

586 


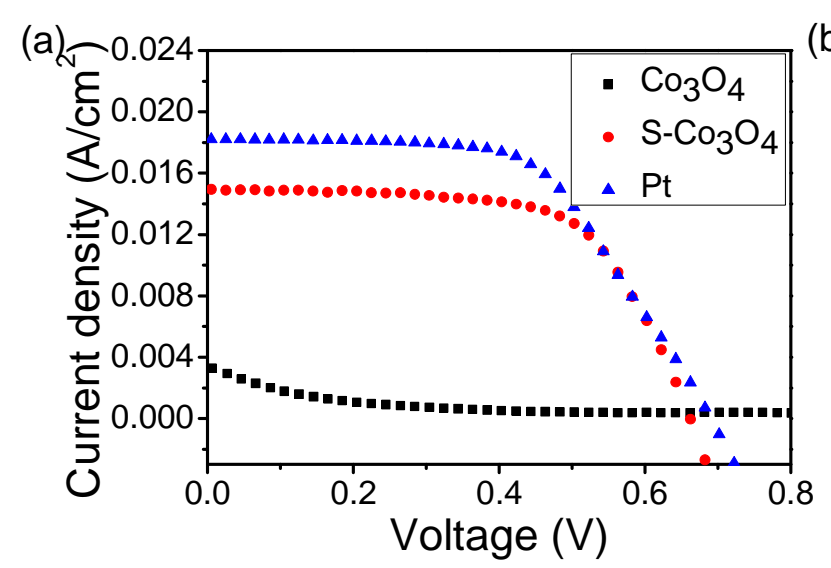

(b)

(c)

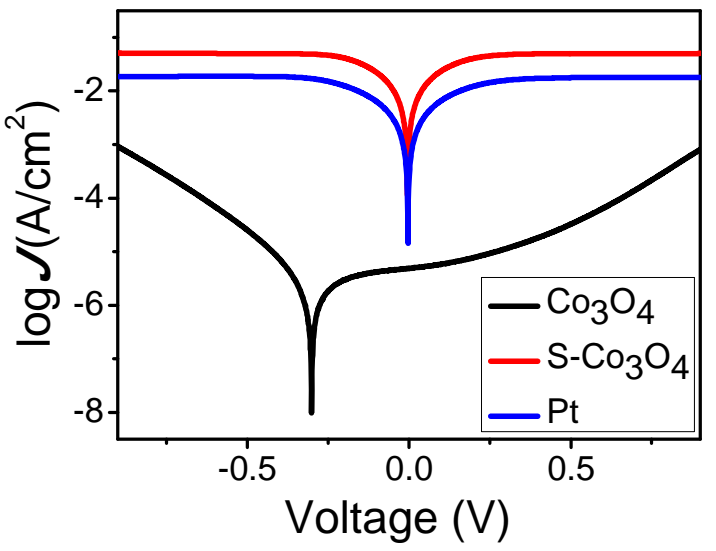

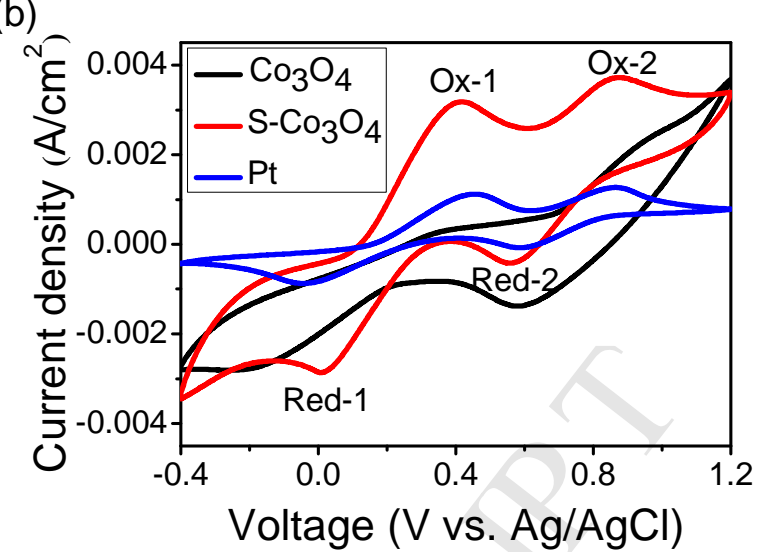

(d)

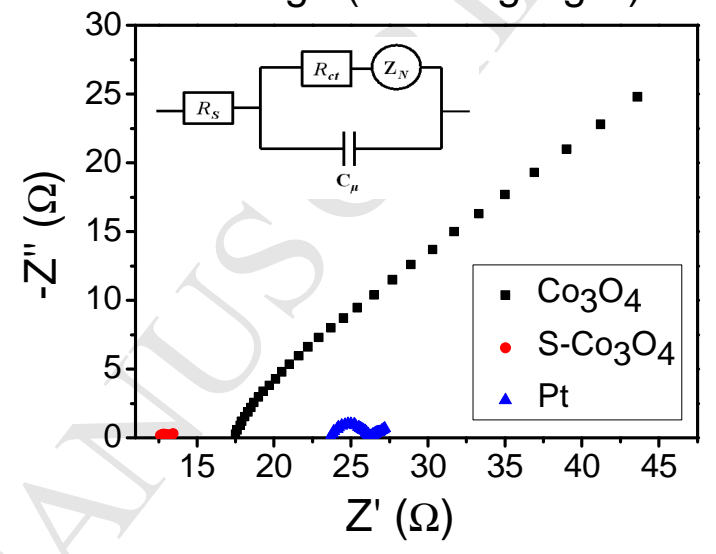



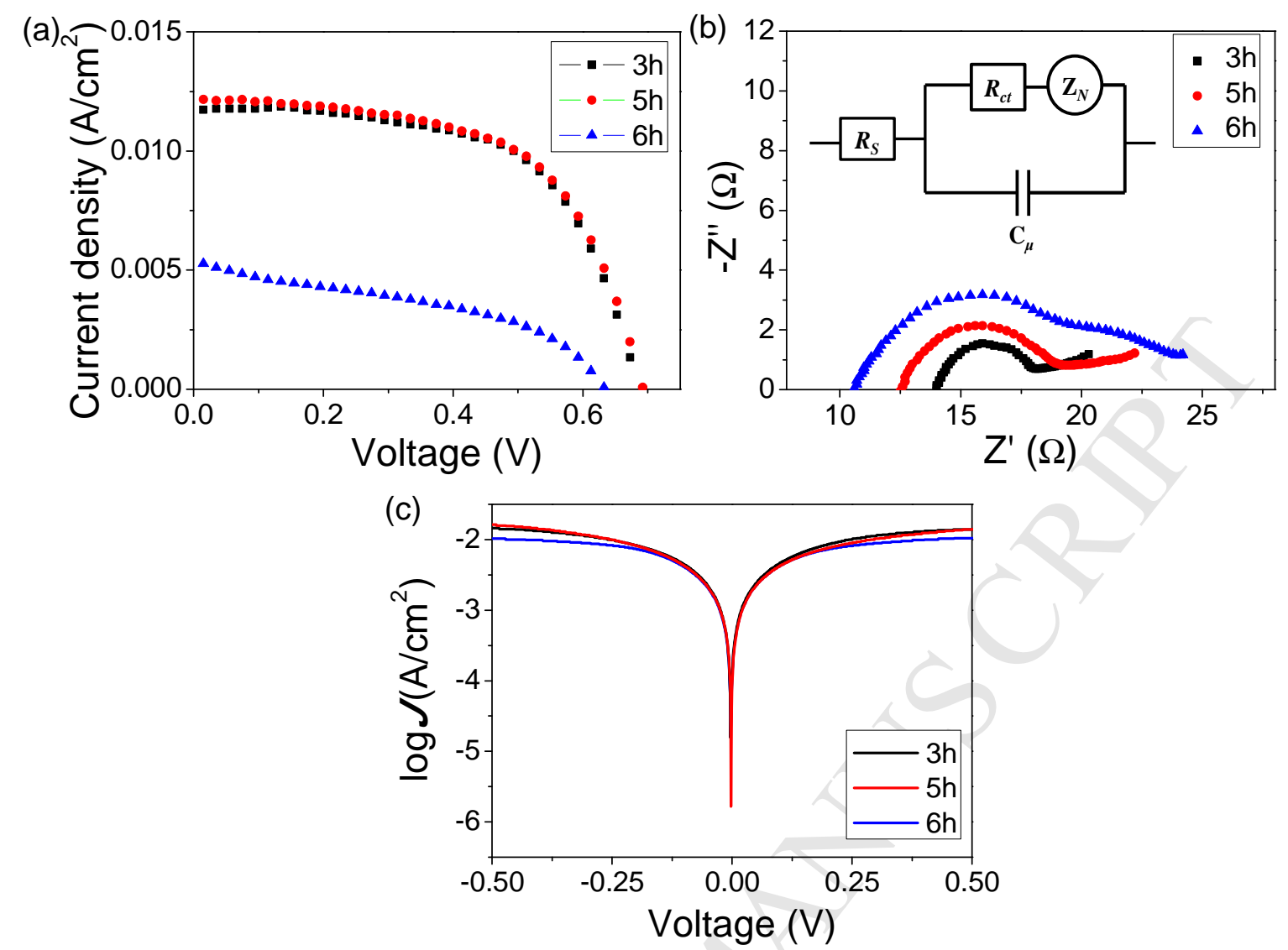

Fig. 6 

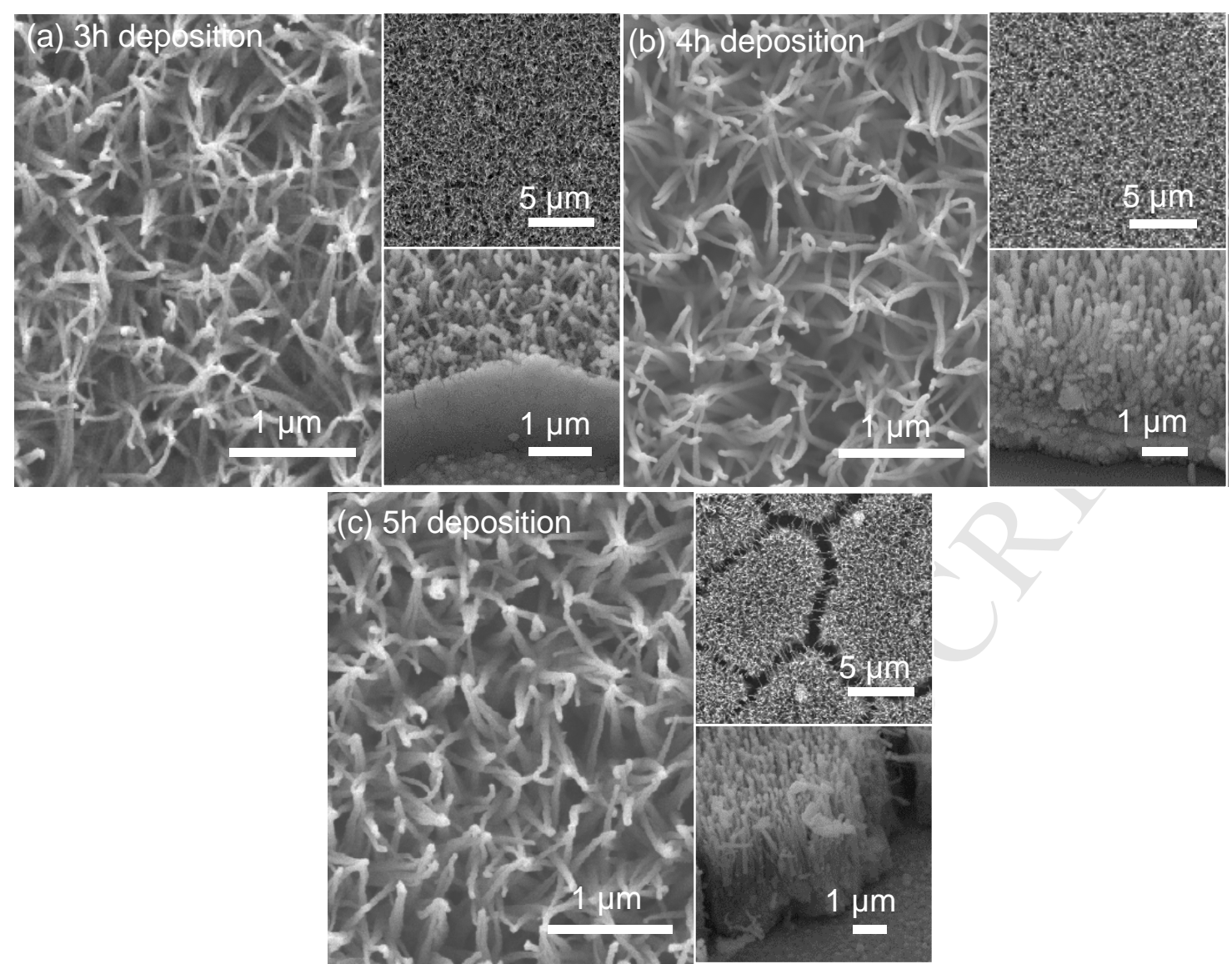

593 Fig. 7

594 

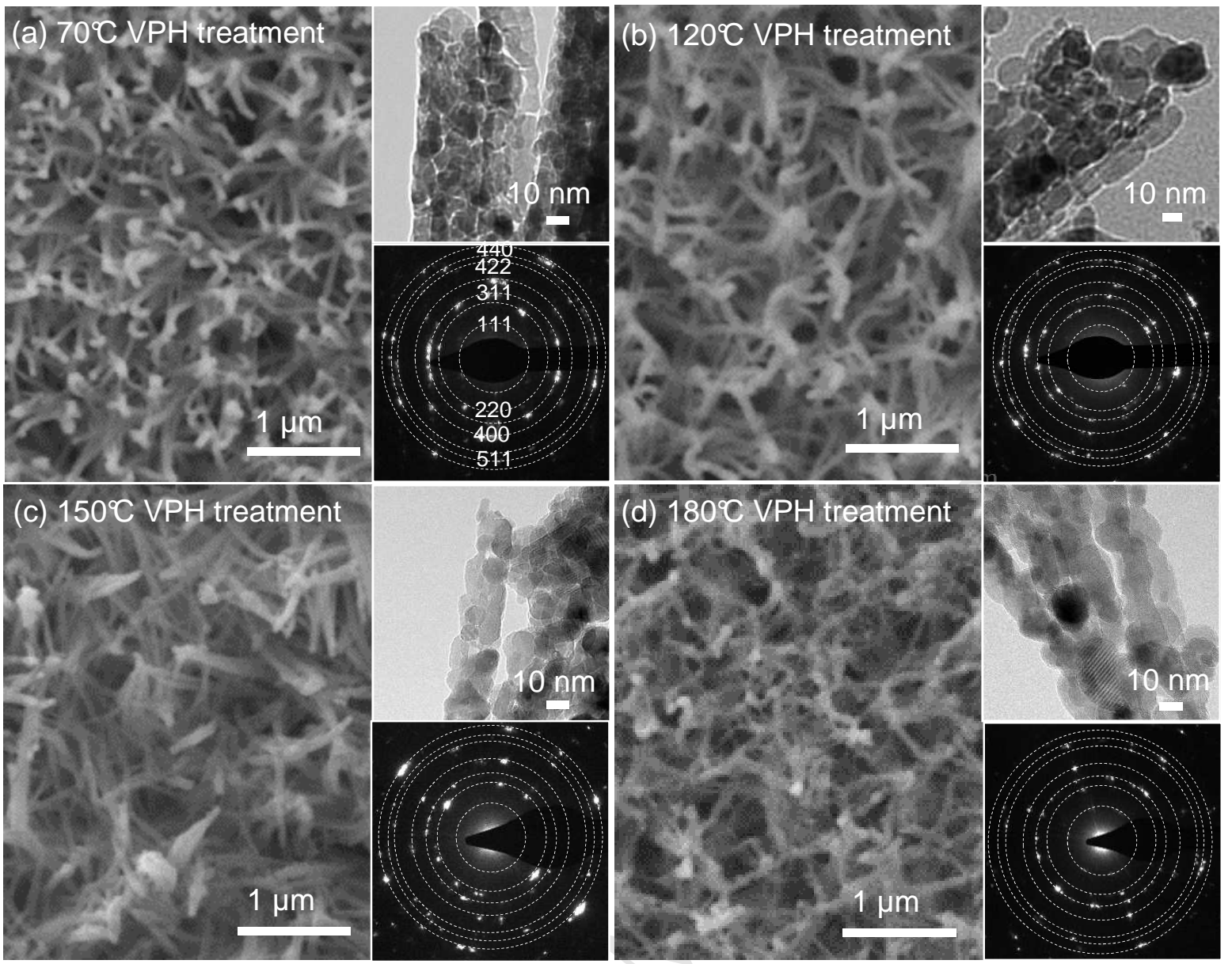

595

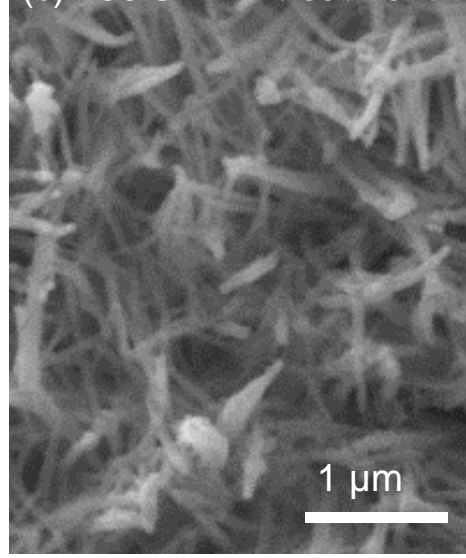

596

Fig. 8

597 
(a)

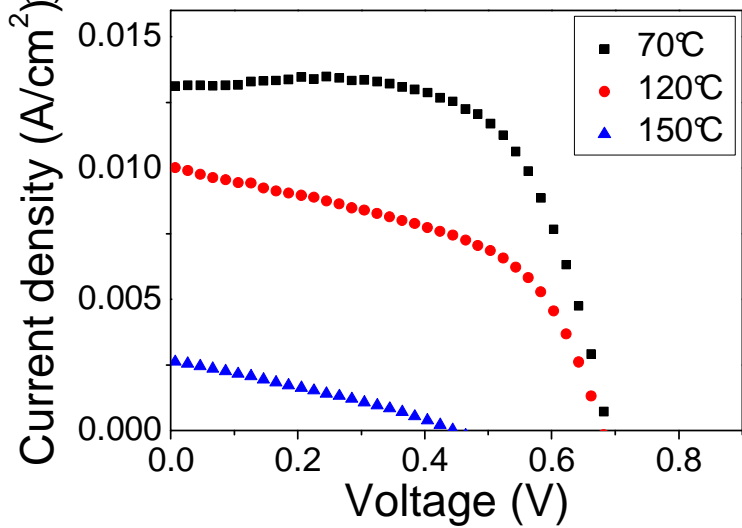

(c)

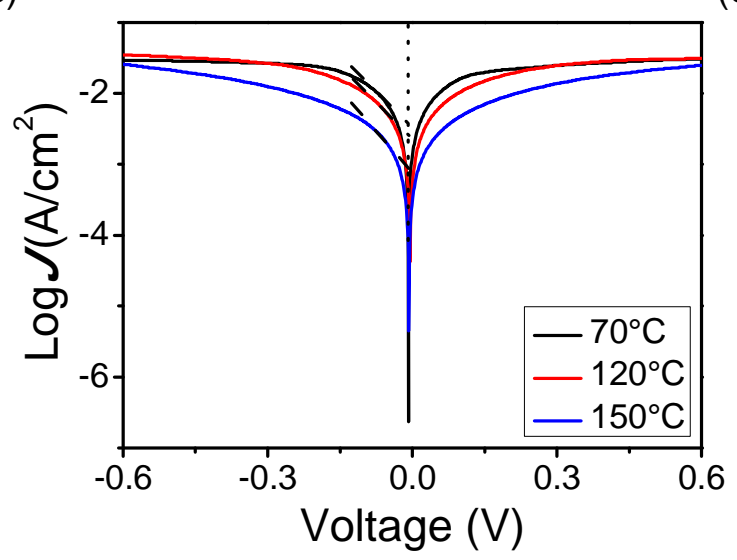

(b)

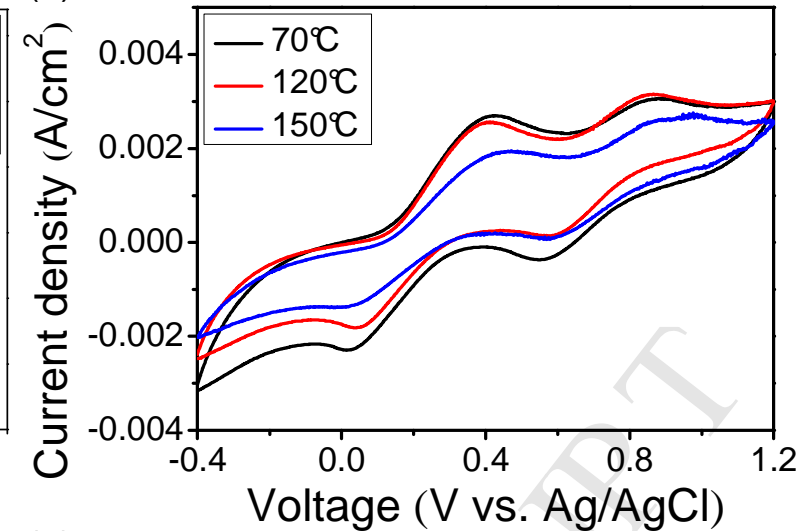

(d)

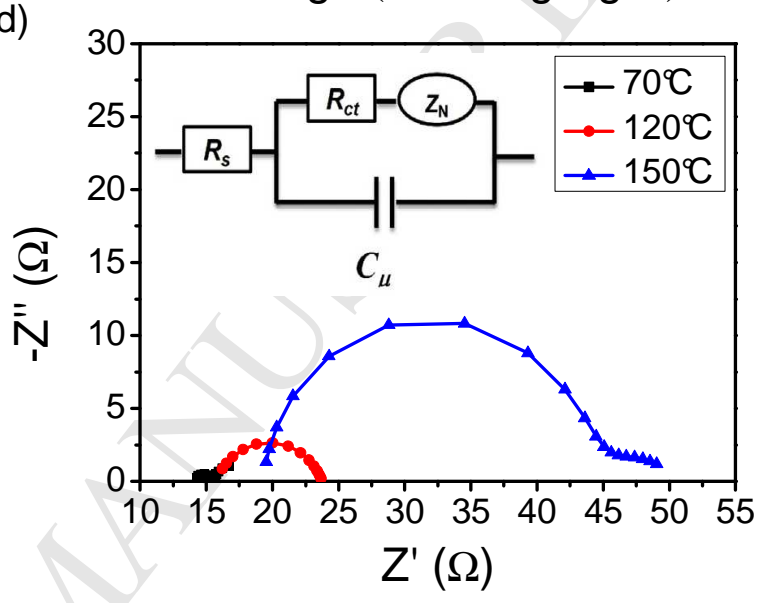

599

Fig. 9 

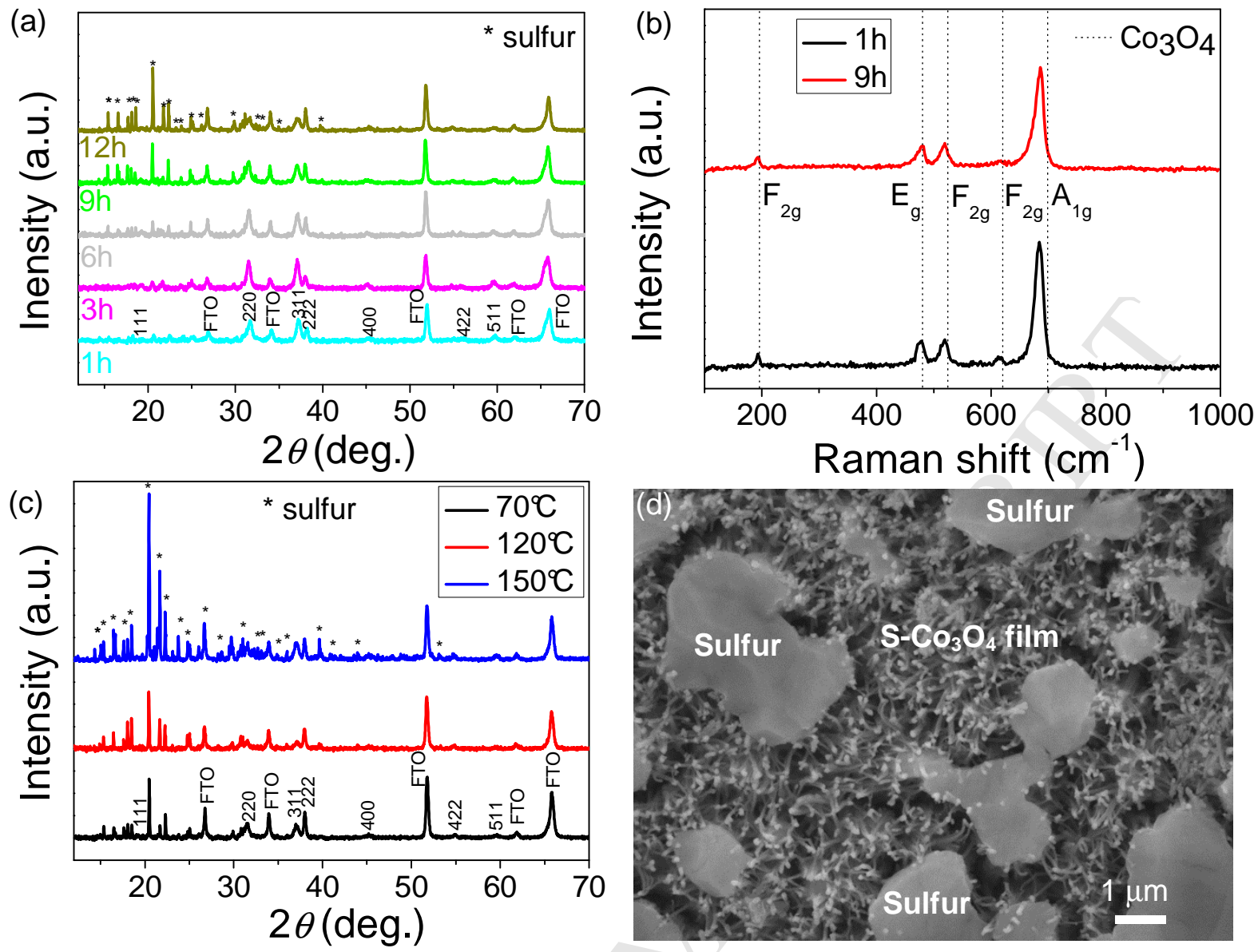

602

Fig. 10 

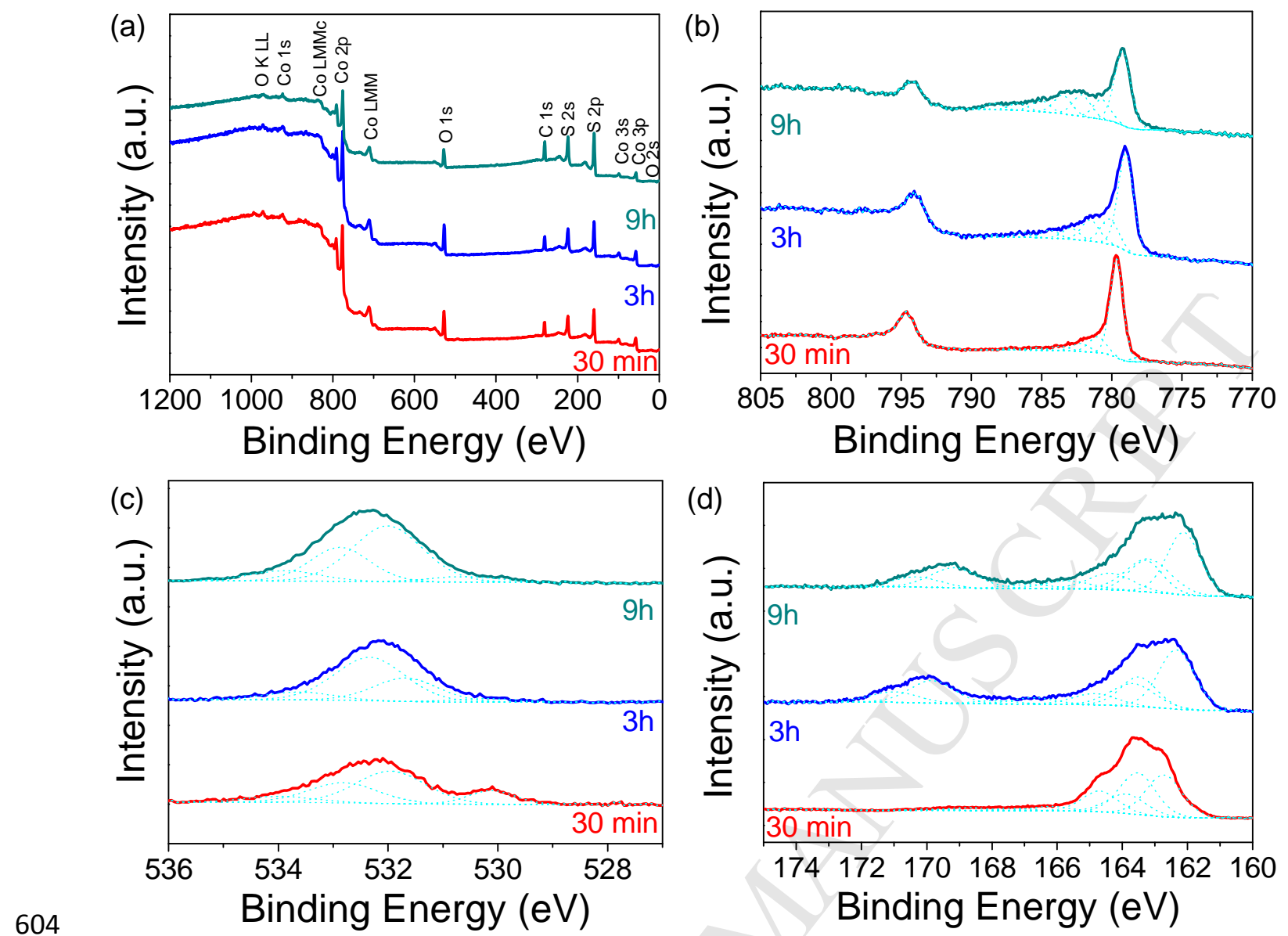

605

Fig. 11 
(a)

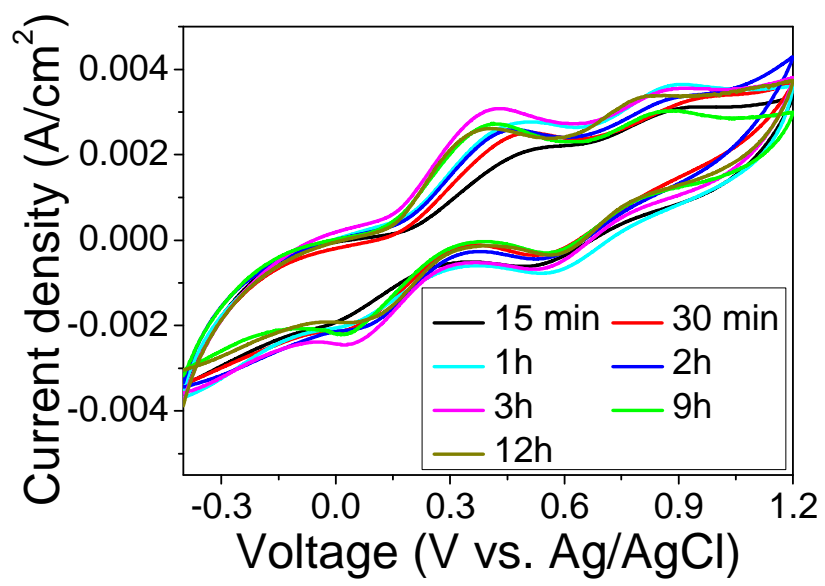

(b)

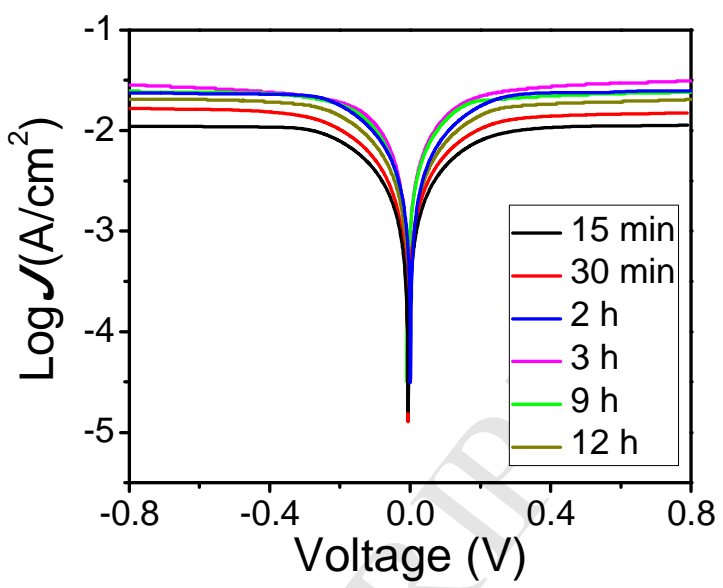

(c)

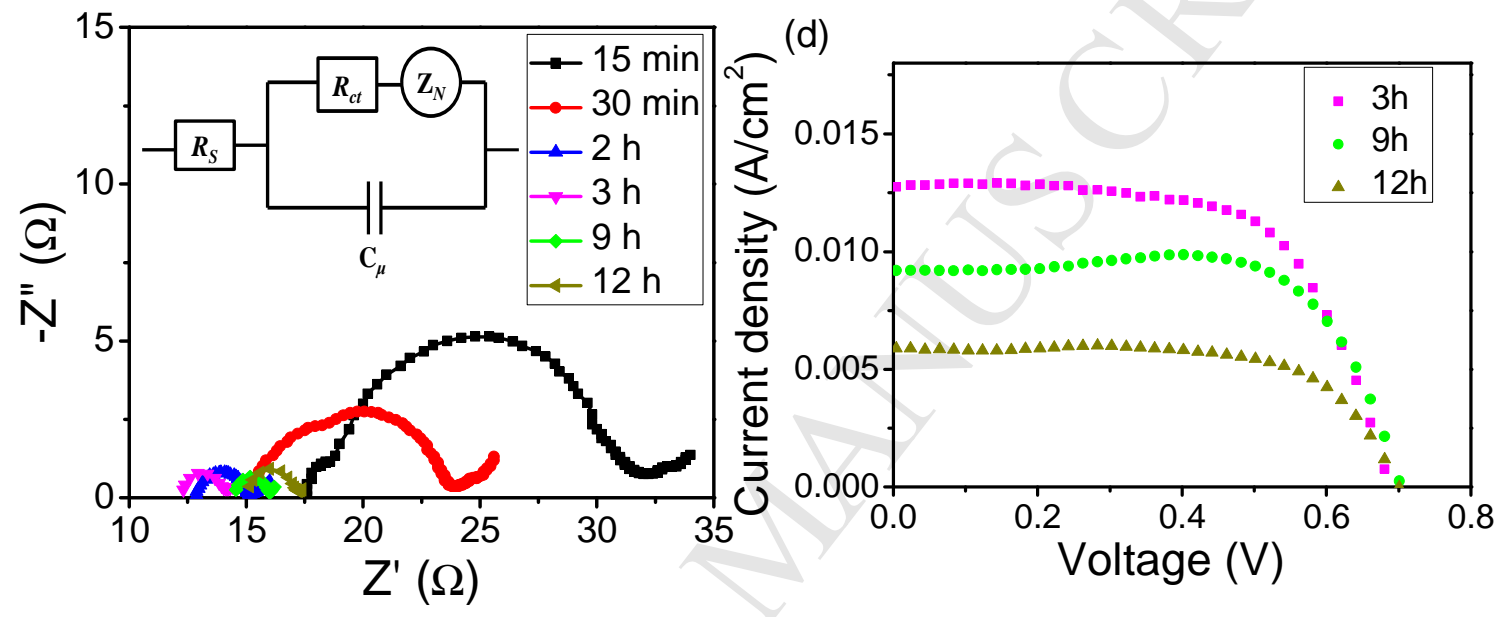

608

Fig. 12 


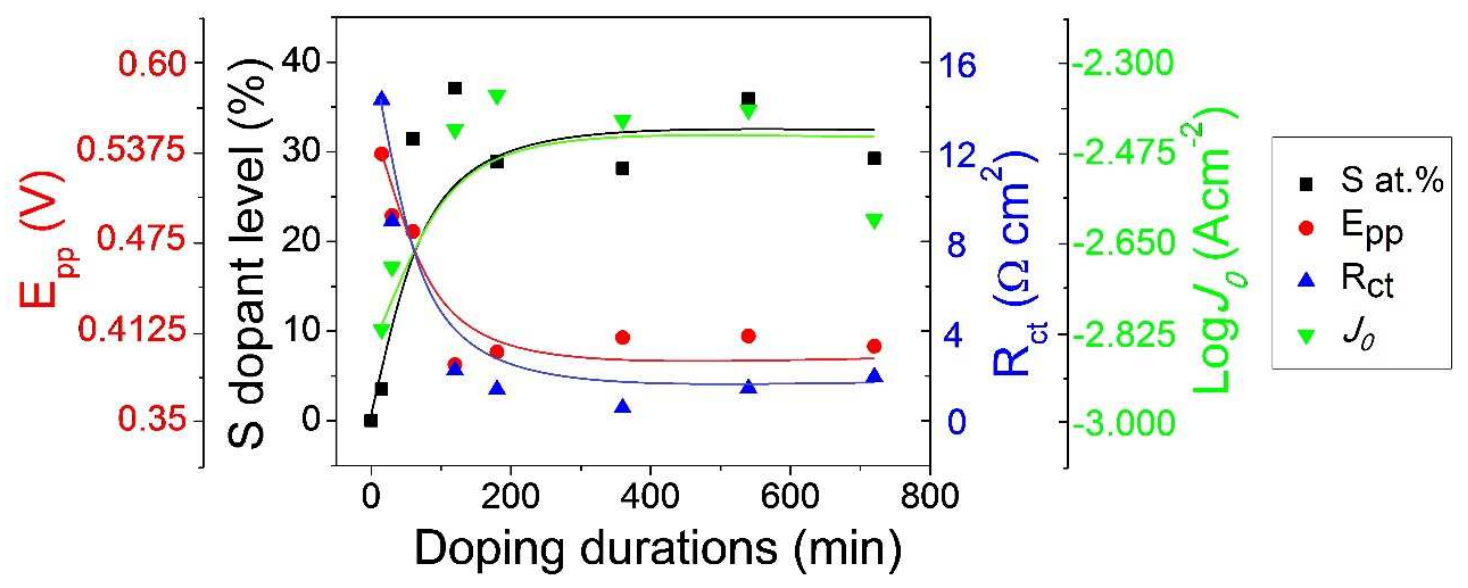

610

Fig. 13

612 


\section{Highlights}

- $\mathrm{S}_{-} \mathrm{Co}_{3} \mathrm{O}_{4}$ films prepared via $\mathrm{VPH}$ approach show excellent activities towards IRR.

- Best activity is achieved by balancing structural integrity and S dopant density.

- A close correlation of activities with dopant levels has been confirmed. 


\section{Accepted Manuscript}

Sulfur-doped cobalt oxide nanowires as efficient electrocatalysts for iodine reduction reaction

Wentao Liang, Kaicai Fan, Yemei Luan, Zhijin Tan, Mohammad Al-Mamun, Yun Wang, Porun Liu, Huijun Zhao

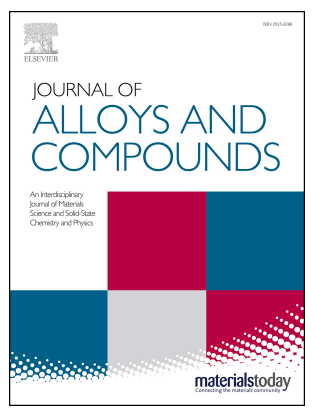

PII: S0925-8388(18)33277-8

DOI: 10.1016/j.jallcom.2018.09.048

Reference: JALCOM 47467

To appear in: Journal of Alloys and Compounds

Received Date: 5 June 2018

Revised Date: 31 August 2018

Accepted Date: 4 September 2018

Please cite this article as: W. Liang, K. Fan, Y. Luan, Z. Tan, M. Al-Mamun, Y. Wang, P. Liu, H. Zhao, Sulfur-doped cobalt oxide nanowires as efficient electrocatalysts for iodine reduction reaction, Journal of Alloys and Compounds (2018), doi: 10.1016/j.jallcom.2018.09.048.

This is a PDF file of an unedited manuscript that has been accepted for publication. As a service to our customers we are providing this early version of the manuscript. The manuscript will undergo copyediting, typesetting, and review of the resulting proof before it is published in its final form. Please note that during the production process errors may be discovered which could affect the content, and all legal disclaimers that apply to the journal pertain. 